\title{
A Model of Positive Tears
}

Janis H. Zickfeld ${ }^{1,2 *}$, Beate Seibt ${ }^{1,3}$, Ljiljana B. Lazarević ${ }^{4}$, Iris Žeželj5 ${ }^{5}$ Ad Vingerhoets ${ }^{6}$

\author{
${ }^{1}$ Department of Psychology, University of Oslo, Oslo, Norway \\ ${ }^{2}$ MZES, University of Mannheim, Mannheim, Germany \\ ${ }^{3}$ Instituto Universitário de Lisboa (ISCTE-IUL), Lisboa, Portugal \\ ${ }^{4}$ Institute of Psychology/Laboratory for Research of Individual Differences, University of Belgrade, Serbia \\ ${ }^{5}$ Department of Psychology, University of Belgrade, Belgrade, Serbia \\ ${ }^{6}$ Department of Clinical Psychology, Tilburg University, the Netherlands
}

Word Count: 14699

Note. Preprint ahead of peer-review. Cite at own risk.

*Corresponding author

Janis H. Zickfeld

jhzickfeld@gmail.com 


\begin{abstract}
Although several scholars acknowledge the existence of tears of joy, there is little systematic theoretical or empirical evidence on how positive tears are experienced, what elicits them, what actions or impulses they motivate in the crier, how they differ from tears of sadness or distress and whether there are different types. We systematically investigated these issues and drafted a first taxonomic model of positive tears. Drawing on more than 1500 reports of positive tears and including 13124 participants from 40 diverse countries and 24 languages, the studies employed a strong mixture of quantitative and qualitative techniques. The final results showed evidence of the occurrence of positive tears and found four qualitatively different types and profiles that we termed achievement, beauty, affection, and amusement tears. Achievement tears are often shed in contexts of extraordinary performance or when someone overcomes an obstacle and often include feelings of pride. Beauty tears occur commonly in situations of overwhelming elegance or beauty, including nature, music or visual arts, and feature feelings of awe or experiencing chills. Affectionate tears are often experienced in situations including unexpected kindness or exceptional love such as wedding ceremonies or reunions and often feature feelings of warmth, increased communality, and feeling touched or compassionate. Finally, amusement tears are shed when something especially funny occurs and include feelings of amusement or lightness and the inclination to laugh or giggle. We also investigated cross-cultural and inter-individual differences with regard to these categories and discuss limitations and implications of our taxonomy of positive tears.
\end{abstract}

Keywords: emotional crying, tears of joy, positive emotions

Words: $250 / 250$ 


\section{A Model of Positive Tears}

Horace, this is it! He asks the girl if maybe they could marry. When she says "Gladly,"

Horace cries.

Electric Light Orchestra. The Diary of Horace Wimp.

Obviously, Horace Wimp is experiencing positive affect when proposing to his girlfriend, but why does he start tearing up? Much research on the causes and antecedents of crying has focused around negative aspects, such as sadness (Vingerhoets, Boelhouwer, Van Tilburg, \& Van Heck, 2001), distress, helplessness (Miceli \& Castelfranchi, 2003), and also depression (Kraemer \& Hastrup, 1986; but see Vingerhoets, Rottenberg, Cevaal, \& Nelson, 2007). Visible tears have also been linked consistently to vocal and facial expressions of sadness (e.g., Cordaro, Keltner, Tshering, Wangchuk, \& Flynn, 2016; Sauter, Eisner, Ekman, \& Scott, 2010). In addition, most theories accounting for adult crying have focused mainly on the negative aspects. For example, psychoanalytically oriented clinicians argued that joyful events involve crying because of unfulfilled wishes and negative experiences (Wood \& Wood, 1984) or that emotional tears are always negative (Feldman, 1956; Weiss, 1952).

However, already René Descartes (1989) stressed the positive aspects of crying. In his treatise The passions of the soul, Descartes explained that tears are not solely reflecting sadness but always contain aspects of love. Mirroring Descartes, recent conceptualizations of adult crying have acknowledged the existence and importance of positive tears ${ }^{1}$ in addition to more negative and distressing forms of crying (Millings, Hepper, Hart, Swift, \& Rowe, 2016; Rottenberg, Bylsma, Wolvin, \& Vingerhoets, 2008; Scheirs \& Sijtsma, 2001; Vingerhoets \& Bylsma, 2015). Still, there is virtually no systematic data available on how positive tears are categorized, differentiated, and what kind of emotions they are a component of (for an exception see Hoffman, Garg, \& González-Mujica, 2013; Vingerhoets, 2013). The present research

\footnotetext{
${ }^{1}$. Throughout the text, we refer to positive tears when considering emotional tears that are experienced as positively valenced. Emotional tears do not include instances of shedding tears due to irritation to the eye. We also focus specifically on the visible aspect of crying, tears and do not consider vocalizations or configurations of facial muscles.
} 
aims at filling the gap of knowledge on positive tears and provides a systematic descriptive model of positive tears. Based on qualitative and quantitative empirical approaches across several different cultures, we suggest a model that is taking into account differences in positive tears and fits previous research on emotional crying.

\section{Emotional Crying: Theoretical Approaches}

Emotion researchers have called the study of human emotional crying a riddle (Vingerhoets \& Bylsma, 2015). Surprisingly, Darwin (1872) attached no purposeful and adaptive function to emotional tears, but researchers from disciplines such as anthropology, ethology, and psychology have contradicted him. Psychoanalysts, on the one hand, have regarded human crying as a safety valve to release excessive emotional energy when emotions are too intense (Sadoff, 1966). Other researchers have argued that crying is the consequence of a loss of control in situations in which one feels helpless and powerless (Frijda, 1986). Such a state of helplessness might also be related to the experience of extremely positive emotions (Aragón, Clark, Dyer, \& Bargh, 2015; Vingerhoets \& Bylsma, 2015). A more cognitive perspective has been taken by Efran and Spangler (1979) who argued that crying is the product of an arousal activation process that is reappraised and that leads to recovery. Such arousal might be caused by incongruent cognitions or an emotional conflict, which is resolved by the shedding of tears. In addition to such a cognitive perspective, other researchers have proposed that tears serve mainly a communicative signal function (Kottler, 1996; Murube, Murube, \& Murube, 1999). Thereby, tears signal bonding or attachment motives. Murube and colleagues speculated that tears are a means of requesting help, but also at a later stage of development of offering help. They also noted that negative emotions, such as loneliness or helplessness, are always accompanied by requesting help, whereas offering help might be driven by both negative and positive emotions.

As noticed by Vingerhoets et al. (2001), most theoretical approaches have focused on primarily negative situational contexts often involving distress or sadness. Only the approaches by Murube and colleagues (1999) on communicating help and the idea that positive emotions might lead to a state of helplessness seem to account for positive emotions specifically. Some scholars challenge the notion that positive tears exist at all (e.g., Feldman, 1956). More specifically, they suggest that people only cry in seemingly positive situations, when there is some sadness or tragedy at the background. As an example, consider the Dutch horsewoman Anky van Grunsven who shed tears when she received her Olympic gold 
medal and explained that these were not happy tears, but they resulted from the fact that her father passed away some months earlier and that he could not witness this special achievement of his daughter. Others claim that the high intensity of positive emotions and in particular the incapacity to adequately express them might result in feelings of being overwhelmed or helplessness, which explain the positive tears (Vingerhoets \& Bylsma, 2015).

\section{Positive Tears}

By positive tears, we refer to emotional crying that is in general appraised and evaluated as positive in affect and includes rather positive emotions such as joy or admiration. Sometimes researchers have also referred to it as tears of joy (Adamson, 1980; Hoffman et al., 2013) or tears of wonder-joy (Braud, 2001). While infants primarily express tears because of distress or pain (Rottenberg \& Vingerhoets, 2012), positive tears seem to become more frequent in adults (Denckla, Fiori, \& Vingerhoets, 2014; Vingerhoets \& Bylsma, 2015). In fact, studies revealed that tearfulness because of tender feelings increases with age (Williams \& Morris, 1996). Interestingly, several studies also reported that men were more likely to cry because of positive reasons than women (Vingerhoets \& Becht, 1997; Williams \& Morris, 1996) or found no gender differences (Hoffman et al., 2013), in seeming contrast to the consistently reported higher crying frequency for women (van Hemert, van de Vijver, \& Vingerhoets, 2011).

Historically, researchers have early on recognized that individuals shed tears due to positive reasons, next to the more prominent experience of shedding tears due to sadness or frustration (Borgquist, 1906; Lund, 1930; Young, 1937; Löfgren, 1966; Bindra, 1972; Frey, Hoffman-Ahern, Johnson, Lykken, \& Tuason, 1983; Frey, 1985; Kottler, 1996). For example, surveying students, Bindra identified a category of elation including situations such as reunions, reciprocation of love, or aesthetic stimuli among the more negative categories of dejection and anguish.

To date, there are, to our knowledge, at least four contributions that have particularly focused on categorizing positive tears. First, in an unpublished thesis, Damen (1999) studied the feeling of being touched to tears using semi-structured interviews and a survey among students. Results revealed that aesthetic and social stimuli were mentioned most frequently. Based on a factor analysis three different factors were identified: aesthetic-related themes (e.g., art, nature, music), sentiment-related themes (e.g., cute puppies) and social-related themes (e.g., weddings, reunions). 
Using introspection, anecdotal evidence, and qualitative inquiries, Braud (2001) described the occurrence of tears of wonder-joy. The author argued that such emotional states often involve goosebumps or chills, warm feelings in the chest and feelings of, amongst others, wonder, gratitude, love, awe, or compassion. In addition, he presented a list of elicitors or circumstances of positive tears, including experiences of nature or beauty, witnessing kindness or bravery, and experiencing closeness or connection amongst others.

Finally, the two most comprehensive categorization of positive tears to date have been offered by Vingerhoets (2013) and Hoffman et al. (2013). Hoffman and colleagues conducted a systematic study on tears of joy in an Indian sample. Collecting reports from 131 individuals, they derived 15 different categories through content-coding including: birth of a child, observing a child reaching a milestone, romantic love, non-romantic affection, personal achievement, identification with fictional characters, reunion, reflection of one's life, recovery from disease, a significant other's recovery, aesthetic delight, religious experiences, laughter, material gain, and witnessing an act of goodness. Categories including affection and achievement were reported most frequently, while laughter or religious experiences occurred rather infrequently.

Vingerhoets (2013) provided a list of antecedents of emotional crying that is rather similar to the one provided by Hoffman and colleagues (2013). Among the positive antecedents were specific events such as the birth of a child, wedding, and reunion, more affective categories such as harmony, ultimate happiness, rapture, social aspects including social bonding, union, achievement categories such as victory, success, achievement, awesome, powerful and extraordinary performance, moral aspects including justice, altruism, world is good, and other categories including young, with potential, tender lovemaking, and orgasm. However, this varied list was not based on specific observations or evidence, but rather a theoretical draft by Vingerhoets (2013).

A more empirical evaluation was provided by Denckla et al. (2014). Using a panel of nearly 5000 Dutch participants, they assessed the power of different antecedents to solicit emotional tears. Their 28item questionnaire resulted in the identification of four different factors that they labeled attachment tears, societal tears, sentimental tears, and compassionate tears. Attachment tears included aspects such as the birth of a child or someone dying. Societal tears featured aspects such as a conflict in a group or other themes related to group processes. Sentimental tears included achievement aspects, but also items such as 
feeling happy. Finally, compassionate tears featured items such as feeling lonely or homesick. In general, there is no easy distinction between positive and negative tears with regard to the four proposed categories. Based on the theme of these items, positive tears seem to be mostly part of the attachment and sentimental categories. However, both categories feature negative aspects as well.

Similarly, Scheirs and Sijtsma (2001) factor analyzed the 54 items on crying proneness of the Adult Crying Inventory (ACI) retaining three main factors termed distress, sadness, and joy. The joy factor included items such as "I cry when watching/hearing an admired person", "I can be moved to tears by the beauty of natural scenes", "I cry when someone does something very special for me/someone", and "I cry when I feel very happy”. This factor was by and large replicated by Millings et al. (2016).

In sum, many researchers studying emotional crying have theorized or provided evidence for the existence of positive tears in general. Yet, different scholars suggested several various themes that might be regarded as positive tears. Specifically, tears due to aesthetic stimuli such as nature, music, or poems have been mentioned rather frequently (Bindra, 1972; Braud, 2001; Damen, 1999; Hoffman et al., 2013; Kottler, 1996; Lund, 1930; Tan \& Frijda, 1999). In addition, many scholars identified aspects that involve increased communality or social bonding such as reunions, weddings or union (Bindra, 1972; Braud, 2001; Damen, 1999; Denckla et al., 2014; Frey et al., 1983; Hoffman et al., 2013; Kottler, 1996; Löfgren, 1966; Murube et al., 1999; Tan \& Frijda, 1999; Vingerhoets, 2013). Other more frequently mentioned aspects seem to contain particular achievements (Denckla et al., 2014; Hoffman et al., 2013; Vingerhoets, 2013), or tears of laughter (Hoffman et al., 2013; Lund, 1930; Young, 1937).

\section{The occurrence of positive tears}

The occurrence of positive tears seems to be more common as one grows older (Vingerhoets \& Bylsma, 2015; Williams \& Morris, 1996). However, there is little information on how often adults experience positive tears. Across two studies exploring adult crying, Vingerhoets, van Geleuken, Van Tilburg, and Van Heck (1997) identified joyful themes in less than 5\% of the reports. Further, in an international study on adult crying, including 37 countries, $15,7 \%$ of answers were identified as reporting a crying episode that included positive antecedents (Bylsma, Vingerhoets, \& Rottenberg, 2008). The most direct evidence comes from Hoffman and colleagues (2013) sampling Indian participants. They found that tears of joy were experienced at least several times a year by the majority of participants. Considering these studies, it seems that the prevalence of positive tears is rather low in comparison to negative tears. 
This picture is not surprising with regard to the last decades of research on emotional crying, which has heavily focused on helplessness or sadness (e.g., Vingerhoets \& Bylsma, 2016). Another problem might be that people associate tears primarily with something negative such as sadness or distress, which may explain why study participants more easily remember and report negative events than positive crying antecedents in retrospective self-report studies (see Vingerhoets et al., 2001). In fact, research exploring positive emotions associated with emotional crying points to the possibility that positive tears might be experienced more often than identified by the reviewed data (e.g., Zickfeld, Schubert, Seibt, Blomster, et al., 2018).

\section{Positive emotions and emotional tears}

Vingerhoets and colleagues (2001) concluded that emotional tears often include a blend of emotions, which they identify, amongst others, as sadness, powerlessness, anxiety, or frustration. Notably, research has also associated crying with more positive emotions. For example, Darwin (1872) and James (1890) already linked crying to tender feelings.

Other scholars have referred to a concept called being moved, which includes for example "tears [that] are shed during sentimental movies" (Scherer \& Zentner, 2001, p. 384). Recent years have seen further conceptualizations of the emotion of being moved (Cova \& Deonna, 2014; Menninghaus et al., 2015; Zickfeld, Schubert, Seibt, Blomster, et al., 2018). In one study, participants provided self-reported emotions and bodily sensations in real-time as they were watching different video clips eliciting strong emotions (Schubert, Zickfeld, Seibt, \& Fiske, 2016). Self-reports of tears correlated highly with selfreports of being moved and happiness by another group. Additional evidence was presented in a study measuring autonomic nervous system activation in responses to different movie clips (Wassiliwizky, Jacobsen, Heinrich, Schneiderbauer, \& Menninghaus, 2017). The authors obtained evidence that highintensity episodes of being moved featured the occurrence of actual goosebumps and self-reported tears. In a recent cross-cultural study spanning 19 different countries, self-reports of tears were highly correlated with self-reported feelings of kama muta (moved by love) in all countries (Zickfeld et al., 2018). Finally, recent findings have identified experiences of being moved (and also tears) with regard to the contexts of love, achievement, and beauty (Strick \& Van Soolingen, 2017). Finally, Tan and Frijda (1999) discussed tears in the presence of sentimentality. 
Next to feelings of being moved, other positive emotions have been occasionally linked to the shedding of emotional tears. One study compared the emotions of joy, gratitude, admiration, and elevation (Algoe \& Haidt, 2009). Participants reported experiencing tears most frequently for admiration in comparison to joy or elevation. Except for Borgquist (1906), theorizing such a link between admiration and tears, a recent review of admiration did not mention crying as a possible expression (Onu, Kessler, \& Smith, 2016). Further, Haidt (2003) argued that emotional tears might often occur in the state of elevation. According to this author, elevation is the experience of perceiving moral excellence, which has been measured with several different emotion labels, such as inspiration, gratitude, admiration, but also being moved (see Thomson \& Siegel, 2016 for a review). Similarly, Braud (2001) argued that positive tears are occurring across a plethora of feelings such as awe, gratitude, or love. Altogether, few empirical evidence linking these positive feeling states to tears exist.

Finally, emotional crying or feeling like crying have been argued to play an essential role in the enjoyment or integration of aesthetic experiences (Pelowski, 2015). This author argues that insight in the context of aesthetics might trigger tears of epiphany or pleasure.

\section{The Present Studies}

Although positive tears have been mentioned frequently throughout the literature on human emotional crying, to date, there exists no systematic attempt to explore their nature and categorize them adequately. While some studies have looked at tears in responses to certain emotions (Damen, 1999; Tan \& Frijda, 1999), other scholars have provided purely theoretical classifications without any underlying empirical evidence (Vingerhoets, 2013), or focused on rather specific samples (Hoffman et al., 2013). The present study tries to fill this gap by providing a systematic taxonomy of positive tears. We thereby pose the questions: What kind of positive tears exist? What elicits positive tears? How are the types of positive tears different from each other? What specific emotions are related to different types of positive tears? How do interindividual differences affect the experience of positive tears?

In order to study positive tears systematically, we rely on some accounts of positive tears from different countries and cultures. We base our findings on data that have been primarily collected for other research questions (Seibt, Schubert, Zickfeld, \& Fiske, 2017; van Hemert et al., 2011; Zickfeld et al., 2018; Zickfeld, Schubert, Seibt, \& Fiske, 2017), but that have not been presented elsewhere and additional data 
and analyses that have been specifically conducted for the present investigation. We make use of a potent mixture of qualitative and quantitative strategies (Tashakkori \& Teddlie, 1998).

First, in Study 1 we qualitatively analyzed positive tears episodes from US and Norwegian participants using thematic analysis (Braun \& Clarke, 2006). Based on the emerging categories of these samples, we constructed the first draft of a coding model of positive tears. We then applied our model to further positive tears episodes by Dutch, Spanish, South African, Serbian, Chinese, Finnish, and Australian participants in Study 2. Based on these preliminary findings, we subsequently formulated our main hypotheses and pre-registered them. We then tested these hypotheses using UK participants in a confirmatory fashion in Study 3. Finally, we explored general aspects and interindividual differences in positive tears in a representative Dutch sample in Study 4a, among 37 different countries in Study 4b, and more specifically across US, Norwegian and Serbian participants in Study 4c. In total, we obtained data from 13124 individuals from 40 different countries, six different continents, and 24 different languages.

For each study, we report how we determined the sample size ${ }^{2}$, all data exclusions (if any), all manipulations, and all measures (see also Supplementary Material). All data files are available at osf.io (https://osf.io/fhqux/) except for parts that might identify participants. All studies were reviewed by the internal review board of the University of Oslo and the respective institution at which the data were collected.

\section{Study 1: Drafting a Model of Positive Tears Using Thematic Analysis}

The main goal of the first study was to gain an overview of what individuals might associate or experience with positive tears. What are the situations in which such emotional tears are experienced, and how can they be differentiated? In order to explore these questions, we asked individuals to report recent situations and experiences of positive tears using a free-response format. Starting with a qualitative inquiry has several strengths and can be especially informative if only a few previous studies have investigated the issues at hand, as in our case (Tashakkori \& Teddlie, 1998).

\section{Method}

\footnotetext{
2. All studies, except for Study 3 and 4c, were originally collected for different purposes. Thus, we were not able to completely control the final sample size. In general, these studies featured quite big samples, and we attempted to account for not being able to perform a proper a-priori power analysis.
} 
Participants. In total, we collected 241 participants (135 US Americans, 106 Norwegian). US participants were recruited on Amazon MTurk and Norwegian participants through an undergraduate research course at the University of Oslo. We excluded participants that did not provide an episode $(n=3)$, obviously reported a negative episode $(n=1)$ and acknowledged that they have never experienced positive tears before $(n=1)$. After exclusion our final sample consisted of 132 US American participants (62 females, 70 males) ranging from 19 to 69 years of age $(M=35.20, S D=11.32)$ and 104 Norwegian participants (74 females, 27 males, 3 other) ranging from 19 to 53 years of age $(M=24.15, S D=5.18)$. Thus, a total of 236 episodes was analyzed. Participants completed the survey in their respective language. ${ }^{3}$

Procedure \& Materials. After giving informed consent, participants were asked to describe an episode in which they "got moist eyes or even shed a tear because of a positive feeling." Participants were instructed to write at least 300 characters and should recount a situation from the last three months. If they could not remember a recent episode, it was possible to report an earlier situation in their lives. Afterward, participants completed some additional measures not focal to the present research question, reported in Seibt et al. (2017) or in the Supplementary Material (1.1). Participants also provided an episode of negative tears not analyzed in the present manuscript. The order of these two instructions was randomized individually. Thus, it was possible that participants had already provided information on a negative episode when recounting the positive one. ${ }^{4}$

\section{Results}

Coding Procedure. We employed thematic analysis (Braun \& Clarke, 2006) to code 236 episodes. For each episode, the main category was established to categorize the main reason for the tear episode (e.g., achieving/making progress towards a goal, nostalgia, unexpected kindness). In addition, we also identified subcategories to disambiguate the different episodes further. Such subcategories included, for example, social contexts (e.g., work, school) or specific milestones (e.g., wedding, graduation, birth) or aesthetic categories (e.g., music, nature). All episodes were coded by a research assistant native in both languages, English and Norwegian. Notably, the research assistant was not aware of any previous research

\footnotetext{
${ }^{3}$ Note that the US sample has been included in Seibt et al. (2016), though not with regard to the present research question.

${ }^{4}$ In both this study and Study 2, we did not observe significant differences in self-report ratings of positive episodes whether they were completed first or second.
} 
on positive tears. We also used an open, iterative coding framework (Srivastava \& Hopwood, 2009). As new categories emerged based on the content, previous episodes could be re-categorized. Moreover, episodes could be categorized into more than just one category.

Categories. An overview of the main categories identified is provided in Table 1, including the frequency of occurrence. Note, that an episode could be coded as belonging to several categories. In the US sample, the most frequent category was termed life transitions of self or close others (US: 14.36\%; NO: $8.45 \%)$, including episodes such as:

My brother got married, and I was thinking about all the times we spent as a kid. I remembered all the times playing with him and all the advice he has given me. I also saw my new sister and couldn't be happier. She is very nice and caring. I was very happy to see them get married and be happy. I enjoyed every moment.

This category included several subtypes such as graduation, wedding/engagement, and the birth of a child/pregnancy. Many of the episodes revolved around significant social life events. In the US sample, another frequent category was termed parent-child relationships (13.26\%) and included episodes such as:

I shed a tear because of a positive feeling whenever my daughter reached a major milestone. I felt so proud of her and proud of myself for helping her reach it. I felt very excited about what was happening and what is still yet to come in the future as sh[e] reaches even more milestones. It makes me feel very happy to get to see her learn and grow and knowing that I'm a big part of that.

This category often involved feelings of pride, especially with regard to an achievement of one's child. Notably, this category was not present in the Norwegian sample, which might be based on the fact that $94.2 \%$ of the sample reported having no children. US participants also frequently mentioned episodes such as unexpected kindness (US: 8.29\%; NO: 9.15\%).

I work in retail, and recently when I was working, I experienced how kind people can be to each other. I was running a cash register one day, and there was an individual who was checking out, and they ended up not having enough money for the groceries that they were buying. It was heartbreaking because you could just see the embarrassment and sadness in their face when I told 
them they didn't have enough. That's when a complete stranger that was standing in line behind this individual offered to pay for what they could not afford. The happiness and joy that were in this individual's face once the man offered to help were so amazing. It was definitely a highlight of my week, and it still gives me such positive feelings to know that there is still kindness that can be shown to each other in this world.

While most episodes were social in nature, we also obtained a few episodes that were categorized as appreciating something beautiful (US: 1.10\%; NO: 5.63\%).

I guess it was back in the 90's, it was the first trip I took to the smoky mountains. Of course, it was beautiful everywhere, but I was not expecting the peace that I experienced. I was expecting the beauty. We pulled over on one of the pull-offs that are in a lot of areas when you are driving through the national park. There is like a creek or stream everywhere in the park. We walked down to the stream, and I was really loud because of the rushing water running over the rocks. There was a large rock jutting out over the stream. I climbed on top and sat there, and it was like the whole world disappeared except for that rock me and the rushing water. I never felt so relaxed and inspired in my life. I actually try to recreate that experience again, but I have never ben [sic] able to.

This category featured subcategories, including music or nature. Finally, there were also some minor cases identified as amusement (US: 1.10\%; NO: 4.23\%), including episodes such as:

I experienced this feeling with a friend when we watched the movie Dead Snow 2. Dead Snow was a horror movie about Nazi zombies, and it was entertaining enough for what it was. Dead Snow 2, however, was a direct continuation that also featured Soviet World War II-era zombies. The whole production was just so boldly over the top, we couldn't help but have an intensely positive feeling about it. We laughed until we had tears.

Based on the coding process, we looked for similar categories to be collapsed and merged together. First, we collapsed the categories achieving/making progress towards a valued goal, recovery after adversity/illness, and positive events after adversity, as they all focused on some kind of achievement and overcoming obstacles. Second, we merged expressions of love/carelappreciation, unexpected kindness, receiving financial help, and sharing-emotional moment with someone together, as they all involved some communal acts in a relationship. Third, we collapsed the two categories of life transition of 
self or close others and relationship changes as they both implied significant events. Fourth, appreciating something beautiful included mostly aesthetic experiences and was different from the other categories and thereby warranted being an own category. Finally, we identified amusement as the final main category. The remaining categories could be subsumed under these five newly constructed main categories.

Remembering dead loved ones might often include communal behavior and can be viewed as a significant event. Holidays/events can be easily subsumed under significant events. Parent-child relationships often included some kind of achievement, but also signals of affection by the parent/child. Life is good, harmony can be viewed as appreciating something beautiful. Finally, nostalgia could be applied to all main category as each category can be experienced by remembering past events. Similarly, happiness or sadness are affective tones that can be easily part of all identified main categories.

After reviewing the five main categories and re-reading the episodes, we recognized that significant life events could be grouped into other main categories, mostly the one about achievement and affection. Thus, our preliminary framework based on the first study included four main categories as exemplified and illustrated in Supplementary Figure 1. First, achievement tears include positive tears shed due to great achievement or someone overcoming an obstacle. Second, beauty tears include positive tears shed because of aesthetic stimuli or extraordinary beauty. Third, love or affectionate tears include positive tears shed due to communal acts or significant changes in social relationships such as weddings. Fourth, amusement tears include positive tears that are shed because someone laughs so hard to the extent of tears. Such tears were evoked through humoristic scenes characterized by incongruity, surprise, or exaggeration (Martin, 2007). Each main category includes several subcategories that were identified in the present study. In addition, we argue that all categories can be experienced from three different perspectives: 1) the situation can be experienced actively in that the individual is part of or actively alters the situation; 2) the individual can passively observe the situation that leads to shedding of tears; 3) the situation can be remembered and imagined, which might often involve feelings of nostalgia (see Fiske, Seibt, \& Schubert, 2017, for a similar argument).

\section{Discussion}

The first study employed thematic analysis to form qualitatively different categories of positive tears. Based on 236 episodes from two languages, English and Norwegian, and featuring two distinct samples, one more general population and one including undergraduates, we identified several different 
categories and subcategories. Taking into account previous relevant findings, we ultimately reduced the number of categories to the following four main categories: (1) achievement, (2) beauty, (3) affectionate, and (3) amusement tears. The aspect that all of these categories have in common is that they are all primarily experienced as positive. Notably, it became obvious during the coding process that these categories are not mutually exclusive. Shedding positive tears because of something beautiful might sometimes include affectionate aspects, witnessing something affectionate such as a wedding might also include some kind of achievement if the bridal couple needed to overcome some obstacles.

Importantly, our preliminary framework is supported by previous theoretical research on positive tears. Scholars have mentioned categories including aesthetic (e.g., Damen, 1999; Hoffman, Garg, \& González-Mujica, 2013; Kottler, 1996; Tan \& Frijda, 1999), communal or affectionate (e.g., Bindra, 1972; Denckla et al., 2014; Murube et al., 1999), achievement (e.g., Denckla et al., 2014; Vingerhoets, 2013) and amusing themes (e.g., Hoffman, Garg, \& González-Mujica, 2013; Lund, 1930; Young, 1937). While we are confident that our framework captures the most important aspects of tears, it should be emphasized that the occurrence of aesthetic and amusing positive tears was rather low (see also Hoffman et al., 2013). This might be either driven by the fact that these categories are naturally occurring less frequently or that our method failed to capture these aspects. People might not directly think of situations in which one laughed to the extent of tears when prompted by the expression of positive tears. We will return to this issue in the next studies.

It should be noted that, with all types of research methods, the present approach using thematic analysis is not free of biases (Braun \& Clarke, 2006; Campbell, Quincy, Osserman, \& Pedersen, 2013). As we employed a purely bottom-up approach, we did not have any expectations about the emerging categories and also did not employ a coding scheme. The episodes were, therefore, only coded by one individual, which weakens the internal reliability of the emerging codes. As we also did not employ any a priori hypotheses, we could have ended up with a completely different framework if there was high variability among different coders. However, it should be noted that our results are backed up and supported by previous theoretical research on positive tears. We will turn to a more proper validation of our framework in the next study.

\section{Study 2: Validating the Model of Positive Tears and Exploring Further Aspects}


While our first study focused on drafting a first preliminary model of positive tears, the second study targeted validating such a model and exploring different aspects of it. We thereby used a similar setup as in Study 1 by collecting written episodes about positive tears. In order to validate our framework across different languages and cultures, we included participants from several countries and cultures: Australia, the Netherlands, Serbia, South Africa, China, Finland, and Spain. The reported data were part of the KAVIAR project and primarily collected for a different research question (Zickfeld et al., 2018), and the present analyses have not been reported before.

\section{Method}

Participants. The final sample consisted of 1086 participants (768 women, 269 men, 6 other, 43 missings) with 131 from China ( 81 women, 45 men, 5 missings), 98 from Australia (53 women, 41 men, 4 missings), 45 from South Africa (24 females, 11 males, 10 missing), 156 from Spain (100 women, 52 men, 4 missings), 243 from Serbia (197 women, 44 men, 2 missings), 271 from the Netherlands (199 women, 60 men, 12 missings), and 142 from Finland (114 women, 16 men, 3 other, 9 missings). Participants' age ranged from 18 to $68(M=24.17, S D=8.52)$. We used the exclusion criteria specified by Zickfeld and colleagues (2018): participants were excluded if they did not provide an episode, if their self-reported nationality differed from the collecting site, and/or if they had more than $50 \%$ of missing responses.

Procedure \& Materials. As in Study 1, participants were instructed to recall an event in which they "got MOIST EYES or even shed a TEAR because of a POSITIVE feeling." (emphasis with caps in the original instructions). Participants were again instructed to write at least 300 characters and pick a recent event from the last three months. If they could not remember a recent event, they were allowed to pick an earlier episode. Copying the first study, participants also reported an event in which they got moist eyes or tears because of a negative feeling. After providing each of these two episodes, participants completed the same measures. Presentation of positive and negative instructions was randomized individually.

A detailed account of the measures is provided in Zickfeld et al. (2018) and in the Supplementary Material (2.1). Participants completed the KAMMUS 2.0, a scale intended to measure the emotional experience of kama muta (Zickfeld et al., 2018). This scale includes five different sections. First, participants completed a sensation and physiology section (14 items, three distractor items; e.g., "Moist eyes"). Second, participants were presented with an appraisal section targeting sudden intensifications of 
communal sharing (11 items, two distractor items; e.g., "I observed a phenomenal feeling of appreciating or being appreciated"). These items were worded both in an active ("I felt ...") and a passive ("I observed ...") fashion and participants were asked to indicate whether they actively took part in the described tear episode or instead observed it passively, which in turn presented the respective section. Third, participants completed items on motivation (7 items, two distractors, e.g., "I wanted to hug someone"). Fourth, we asked about the valence of the episode, and whether the respondents had a positive or a negative feeling (two items). Finally, participants completed a section including emotion labels (10 items). This section included items asking for heartwarming, moved, touched, nostalgic moment, poignant experience, felt part of something larger than myself, fell in love, sadness, awe, and amusement. All sections were completed using a 7-point scale, which was anchored at 0 (not at all) and 6 (a lot).

\section{Results}

Coding Episodes. Episodes were coded by five different individuals each fluent in English and the respective language (if not English). All episodes were additionally independently coded by the first authors (except for Serbian). If the second coder was not proficient in a particular language (i.e., Spanish, Chinese, Finnish), the reported episodes were translated by the first coder into English. For the Serbian data, the third and fourth author, both fluent in English and Serbian, coded the categories.

Main coding categories included: no positive tears (0), achievement (1), beauty (2), affection (3), amusement (4) and not possible to code because participants did not provide an episode, an incoherent text or just copied the instructions (NA). Coders could also indicate possible secondary categories, subcategories, the relationship type (i.e., new relation, reinforced relation, restored relation), the context of the episode (e.g., romantic partner, family, work), and how the episode was experienced (active, passive or imagined). Note that we focus primarily on the main coding categories for the present analyses. Interraterreliabilities among the different referees were substantial (Australia: $\kappa=.77$; Spain: $\kappa=.69$; South Africa: $\kappa=.66$; China: $\kappa=.85 ;$ Finland: $\kappa=.81$, Serbia: $\kappa=.94$, Netherlands: $\kappa=.84)$. Differences in coding were resolved by discussion among the coders. The coding framework was adjusted during the coding process, meaning that some new subcategories were created while others were abandoned (see Supplementary Material 2.2). Most importantly, all 1086 episodes could be coded in one of the five main categories (including no positive tears). The final coding model is presented in Figure 1. 
An overview of the final overarching codes is provided in Table 2. In total, episodes were most often coded as belonging to the affectionate category $(596,54.88 \%)$, followed by achievement themes $(318$, $29.28 \%)$. The occurrence of the beauty $(89,8.20 \%)$ and the amusement categories $(32,2.95 \%)$ was rather low. We also obtained a small proportion that did not fit into any of the four positive main categories because it was either clearly negative $(40,3.68 \%)$ or not codable $(11,1.01 \%)$. In general, the occurrence of codes differed significantly across the different countries, $\chi^{2}(30)=50.03, p=.012$. Major differences across the countries included the Chinese and South African samples, which had no episodes coded as amusement. In addition, the Finnish data contained remarkably high frequency of beauty episodes (14\%). Apart from these differences, the general patterns were comparable across countries and languages.

Differences Across Types of Positive Tears. We also explored how the different categories of positive tears differ from each other to further provide construct validity for our model. We thereby compared the four different main categories against each other and employed all negative tears episodes as a control category. As we included data from several countries and participants reported episodes twice, we employed multilevel modeling using the lme4 package in $R$ (Bates, Mächler, Bolker, \& Walker, 2014). Intercepts were allowed to differ across participants, which were nested in country. Category type was always employed as the independent variable and the variable of interest as the dependent variable. ${ }^{5}$ Estimated means for each model are presented in Table 3. For each variable, post-hoc pairwise comparisons were computed using the emmeans package (Russell, 2018) using a Tukey adjustment.

Comparing Positive and Negative Tears. First, we ran a model in order to check whether the positive categories evoked more positive feelings than did the negative ones. As reported in Table 3, all positive categories received high scores of positivity, while these were low for the negative control category. Using pairwise comparisons with a correction, all positive categories differed significantly from the negative cases ( $d s$ from 2.11 to $2.31, p_{a d j}<.001$ ), but differences across the four positive categories were not statistically significant ( $d s$ from .01 to $.23, p_{a d j}>=.911$ ). Thus, they all induced positivity to a similar degree. Similar findings were obtained when focusing on the item measuring negativity. As predicted, negative categories were rated as more negative than the positive ones. The positive categories

\footnotetext{
${ }^{5}$ Exploring country effects, we also computed additional models adding country as a predictor and its interaction with category type. Intercepts were allowed to vary randomly according to participants. We observed several significant interaction effects that are presented and discussed in the Supplementary Material 2.3.
} 
differed significantly from the negative one ( $d s$ from 2.32 to 2.93 ). Among the positive categories, beauty and affection were rated as significantly more negative than the amusement category $(d=.74$ and $d=.60$, respectively).

Additional Sensations Across Types of Positive Tears. In addition, we tested whether participants reported specific sensations for some types of tears. The results for all models are provided in Table 3. First of all, the occurrence of goosebumps was lowest for the amusement category and highest in the beauty category, which differed significantly from the amusement $(d=1.37)$, affection $(d=.44)$, and the negative type ( $d=.53)$ but not from the achievement category $(d=.18)$. Similarly, the experience of chills was lowest in the amusement category and strongest for the beauty tears. This time though, the beauty type was statistically different from achievement $(d=.23)$, amusement $(d=1.02)$, affection $(d=.55)$, but not from negative tears $(d=.06)$. The experience of a warm feeling in the chest was high in all four positive categories and statistically different from the negative tears ( $d s$ from .83 to 1.57$)$. It was strongest in the affection category and differed significantly from amusement $(d=.69)$ and achievement $(d=.17)$, but not from beauty $(d=.10)$. Experiencing some feeling in the chest was equally often reported for the beauty, affection, and negative tears categories, and somewhat less frequent for the achievement type, and lowest for amusement.

Further, feeling choked up, having a lump in the throat, difficulty speaking, and holding one's breath were the most prominent for the negative tears and participants reported significantly lower means for the positive categories. The least reported for amusement was a lump in the throat, while having difficulty speaking was highest for this category across the positive types. For feeling choked up, no differences were found across the positive categories. Holding one's breath was most reported for the beauty category across the positive tears. Using an exclamation like $A w w$ was most commonly reported for the affection category, which differed significantly from the negative tears only $(d=.54)$. In addition, smiling was a commonly reported behavior for all positive categories and differed significantly from negative tears ( $d s$ from 2.34 to 2.67 ). Giggling was most commonly reported for the amusement category and differed significantly from all other types. Finally, feeling buoyant or light and refreshed or energized was most common for the positive tears, while frowning or lowering one's head was most strongly reported for the negative tears. 
Appraisals and Motivation Across Types of Positive Tears. We also explored whether sudden intensifications of communal sharing differed across the different categories (Table 3; calculated as reported by Zickfeld et al., 2018). Negative tears received the lowest ratings of communal sharing, while they were strongest for the affection category differing significantly from amusement $(d=.78)$, achievement $(d=.74)$, beauty $(d=.45)$, and negative tears $(d=1.31)$. Similarly, observing something comical was rated highest for the amusement tears in contrast to the other categories ( $d s$ from 1.82 to 2.51). Finally, experiencing that a connection was broken was uniquely rated highest for negative tears ( $d s$ from .72 to 1.01$)$.

Considering motivation, we found that affectionate tears indicated the strongest ratings for the motivation to approach and act communally (calculated based on Zickfeld et al., 2018), differing significantly from achievement $(d=.56)$, beauty $(d=.75)$, amusement $(d=1.24)$, and negative tears $(d=$ .76). Wanting to be consoled was rated highest for the negative tears and differed significantly from all other positive categories ( $d s$ from 1.28 to 1.78 ). Similarly, feeling like joking was reported most strongly for the amusement category, which differed from all other tear types ( $d s$ from 1.15 to 2.30). All results are displayed in Table 3.

Emotion Labels Across Types of Positive Tears. An overview of the findings for the ten different emotion labels is provided in Table 3. We observed that ratings of heartwarming, moved, and touched were highest for the affectionate tears, followed by beauty. These two categories were not significantly different from each other but differed from the other types. Ratings for nostalgic moment were high for all positive categories except for amusement. On the other hand, poignant experience was strongest for negative tears. Feeling part of something larger than oneself was highest for the beauty tears and differed significantly from all other categories ( $d s$ from .45 to 1.25 ). I fell in love was reported strongest in the affection and beauty categories. Feeling sad was rated highest for the negative tears and differed significantly from all four positive categories ( $d s$ from 2.50 to 3.28). Affection and beauty were both rated as sadder than achievement and amusement. Similarly, feeling awe was most intense for the beauty category and differed significantly from all other categories ( $d s$ from .36 to 1.38). Finally, feeling amused was rated highest for the amusement tears, different from the remaining categories ( $d s$ from 1.65 to 3.43).

Cross-Cultural Differences. A detailed overview of cross-cultural differences is provided in the Supplementary Material (Supplementary Table 1). Here we summarize the major findings. Importantly, we 
do not compare mean ratings across countries but rather effects (Peng \& Nisbett, 1997). Most consistently, Chinese participants reported the smallest differences across the categories. As an example, negative tears were rated as more positive and positive categories as more negative. This tendency could reflect an actual cultural difference, in that Chinese respondents indeed experience more negativity in positive tears or it could be based on a reporting bias. Previous studies emphasized that Chinese participants tend to avoid extreme ratings on response scales (Paulhus \& Vazire, 2007). Further, differences evolved around specific items. For example, South African participants least likely reported goosebumps and chills for beauty tears, while all other countries rated these items highest for this given type. Similarly, Finnish participants reported most often some feeling in the chest for amusement tears, while all other countries reported the least occurrence for this type. Perhaps, these findings reflect actual cultural differences in positive tears. South African individuals might not experience goosebumps when standing in a national park in front of a majestic waterfall. Or Finnish speakers may refer to a specific feeling in the chest when laughing with tears. On the other hand, this could also reflect lexical issues. Possibly, the Finnish expression (Jokin tunne keskellä rintaa) referring to feelings in the chest relates to specific states with regard to amusement but not other emotional reactions.

\section{Discussion}

In the second study, we further validated our model of positive tears. An additional of 1086 episodes from seven different countries were coded with regard to the framework established in Study 1. Participants also completed additional measures assessing sensations or how they felt during the episode. Results from these analyses suggested that the positive tear categories are clearly distinct from negative tears. Moreover, we observed differences across the four positive tears categories further polishing our framework. The updated model of positive tears is illustrated in Figure 1.

The present study supported the distinction between the categories of achievement, beauty, affection, and amusement. Affectionate tears were described most frequently. More than half of all episodes were sorted into this category. The category was rated as involving strong intensifications of communal sharing and motivations to approach and act communally. Affectionate tears were experienced as heartwarming, moving, touching, and participants reported falling in love. Achievement tears were reported as the second most frequent category. They were found to motivate communal intentions and were often labeled as poignant. Perhaps strong feelings of admiration or pride can also elicit tears (Algoe 
\& Haidt, 2009), although not explicitly tested in the present study. From the presented results, it is not obvious whether achievement tears can only be elicited by observing someone else achieving something extraordinary or also by extraordinary achievement by oneself. Beauty tears included high reports of goosebumps and chills and feelings of awe. The category was also described as including a feeling of something larger than oneself. Finally, amusement tears were reported for something comical, and individuals felt more like joking. Similarly, giggling and feelings of amusement were reported highest for this category.

Our findings largely confirm previous theorizations and our findings from Study 1 with more culturally diverse samples. However, the present study had two main disadvantages. First, all analyses were exploratory without any specific a priori hypotheses. This is not entirely problematic as our main approach was mainly bottom-up. The next study focused on a confirmatory approach based on the findings from the first two steps. Second, categories of beauty and amusement were again highly underrepresented, making meaningful statistical comparisons difficult. On the one hand, this distribution might reflect the actual occurrence of these types of tears as found in previous studies (Hoffman et al., 2013), on the other hand, our method might, as already argued in Study 1, have problems in evoking these types of tears. The next study tried to address this problem by directly evoking the different types of emotional tears.

\section{Study 3: Confirmatory Test of a Model of Positive Tears}

The third study tried to address previous issues by not asking individuals to recall any type of positive tears, but rather targeting the four different types directly. Participants were sampled in the UK to test our model in an additional population. In addition, we pre-registered the study and analysis plan and specific hypothesis. The pre-registration of the study is available at https://osf.io/vf5z6/. Analyses not registered a priori are explicitly denoted as exploratory. Based on theoretical evidence and the findings from our previous studies, we predicted that there are four different main types of positive tears that can be qualitatively differentiated based on (1) appraisal patterns, (2) motivational function, (3) bodily sensations, and (4) the feeling labels they elicit.

Our predictions are derived in part based on results from Study 2 and also from the previous theoretical and empirical literature. First, we predict that achievement tears are experienced as someone achieving something extraordinary or overcoming an obstacle, motivate being inspired (Onu et al., 2016), acting communally (Study 2), and accompany emotions including admiration, and pride. We also predict 
that individuals feel energized (Algoe \& Haidt, 2009). Second, we predict that beauty tears are experienced as something extraordinarily beautiful, including aesthetics such as music, paintings or films, nature, or cute puppies and motivate reflective actions (Pelowski, 2015). As observed in Study 2, they should include sensations of chills and goosebumps and emotions such as feeling awe. Third, we predict that affectionate tears are experienced as intensifications in communal acts or by extraordinary communal performance and motivate acting communally (Fiske et al., 2017). They should include a warm feeling (in the chest) and are labeled as heartwarming, moved, touched, or involving love (e.g., Zickfeld et al., 2018; Study 2). Fourth, we predict that amusement tears are appraised by something comical and motivate taking action in general and joking (Fredrickson \& Branigan, 2005; Study 2). They should include behavior as giggling and accompany feelings of amusement and entertained (Study 2).

\section{Method}

Participants. In total, we recruited 449 participants on Prolific.ac. Based on our pre-registered criteria, participants were excluded if they completed less than $50 \%$ of the questionnaire, provided no episode or no meaningful one (e.g., copying the instructions, writing random characters) or spent less than 60 seconds writing an episode, which was recorded using a timer. The final sample consisted of 431 participants (305 women, 123 men, 2 other, 1 missing) with the majority coming from the UK $(424,5$ other, 2 missings). Reported age ranged from 18 to 71 years $(M=35.81, S D=12.52)$. We aimed for at least 100 participants per condition. Power analysis with a power of .90 , an effect size of $f=.20$, and an alpha level of .05 , suggested a final sample of 360 participants.

Procedure \& Materials. After providing informed consent, participants were randomly allocated to one out of four conditions. In each condition, participants were asked to recall an episode in which they got moist eyes or tears because of a positive event as in Study 2. In addition, we manipulated whether that event was described as including aspects of achievement $(n=98$; attaining an extraordinary achievement or overcoming an obstacle), beauty ( $n=108$; including something exceptionally beautiful such as nature, art, or cute objects), affection ( $n=95$; included extraordinary examples of closeness or affection), amusement ( $n=130$; something especially amusing to the point of tears). An overview of the actual prompts is provided in the Supplementary Material (3.1). As in the previous studies, participants were instructed to write at least 300 characters and pick an episode from the last three months. If they could not remember a recent event, they were able to choose one that happened earlier. 
After providing an episode, participants completed sections including items targeting valence (2 items; e.g., "I had positive feelings"), sensations ( 8 items; e.g., "I laughed"), appraisal (7 items; e.g. "I felt an incredible bond"), motivation (4 items; e.g., "I wanted to reflect on the experience"), emotion labels (12 items; e.g., "I felt pride"). Most items were drawn from Study 2, with additional items drafted to account for achievement and amusement categories. All items were assessed on a 7-point scale anchored at not at all (0) and a lot (6). Before completing these items, participants indicated whether they took part actively or passively in the provided episode. Based upon their response, they were presented with appraisal items that were either worded in an active (e.g., "I felt that either I or someone else delivered an extraordinary performance") or observant fashion (e.g., "I observed an extraordinary performance"). Finally focusing on social context, participants completed a dichotomous item targeting whether they were alone or together with other individuals during the episode and provided demographic information. An overview of all items and their distribution is provided in Table 4 and the Supplementary Material (3.2).

\section{Results}

As registered, we collapsed several appraisal items to form a score. The first two items on a bond and closeness were averaged into an affection score, the items on extraordinary performance and overcoming an obstacle were averaged into an achievement score, and the items on beauty and greatness were averaged into a beauty score. Internal consistency (see Table 4) was particularly low for the achievement score, but we still combined the items based on theoretical reasons. In the remainder of the results, we also present findings for each of these items separately. We also computed a kama muta labels score by averaging the items on heartwarming, moved, and touched (Table 4). For all presented analyses, the alpha level was set at .05 .

We ran four pre-registered main models using a multivariate analysis of variance (MANOVA). One model was specified for each positive tear type with a factor coding for type of positive tears as the independent variable in each model. For achievement, we added the achievement score, the achievement motivation item (being inspired), the sensation of feeling energized, and labels of admiration, pride, inspiration, and respect. For beauty, we added the beauty score, the beauty motivation item (reflect), sensations of goosebumps and chills, and labels of feeling awe. ${ }^{6}$ For affection, we added the affection

\footnotetext{
${ }^{6}$ Note that we incorrectly included the item on feeling inspired in the beauty model in the pre-registration, while it should be included in the achievement model.
} 
score, the affection motivation item (committed to the relationship), the sensation of warmth in the chest and labels of heartwarming, moved, touched, and love. Finally, for amusement, we added the amusement item, the amusement motivation item (joking), sensations of feeling buoyant, laughing and giggling, and labels of feeling amused and entertained. For each model, we followed the main test with planned contrast of the focal tear category with all other categories. As we employed planned contrasts, we did not adjust for multiple comparisons.

As registered, we first ran a one-way ANOVA with positive valence as the dependent variable and type of tears as the independent variable to check whether the different tears were experienced differently with regard to the intensity of positivity. We did not obtain a significant main effect for type of positive tears, $F(3,426)=.58, p=.63, \eta^{2}=.004$, suggesting that the intensity of positive valence did not differ across the four types (see Table 4). We repeated the same model with negative valence as DV and similarly obtained no evidence for a significant main effect, $F(3,422)=1.83, p=.16, \eta^{2}=.013$. These findings were similar to the ones obtained in Study 2.

Main Analyses. When focusing on our main models, we recognized that a high percentage of written episodes did not fit the instruction for that respective condition. For example, episodes in the beauty condition often contained descriptions of achievement or affection and episodes in the amusement condition sometimes included themes focusing on affection or beauty. These blends might be explained by the fact that participants were not always able to recollect an episode that fit the specific instructions and rather provided reports of an episode including any positive valence. On the other hand, it is also possible that participants did not read the instructions adequately. In order to address the possible issue of the manipulation, two coders independently coded all reported episodes based on the coding scheme developed in the previous studies. One coder was not aware of the hypotheses of the present study, and interrater reliability was considerable $(\mathrm{k}=.78[.73, .83])$. A chi-square test comparing the type of tears condition with our final codes revealed considerable differences, $\chi^{2}(9)=244.66, p<.001, \varphi=.43$. Therefore, in contrast to our pre-registered criteria, we will use this coding in the main analyses of the present study. In total, 143 episodes were coded as achievement, 38 as beauty, 178 as affection, and 72 as amusement. Results using the original type of tears condition factor are presented in the Supplementary Material (3.3). In general, results were similar for the main variables of interest, but often more nuanced 
when employing the coding factor. An overview of all ratings across the four conditions is provided in Table 4.

For the achievement model, we obtained an overall significant main effect, $F(3,427)=10.40, p<$ .001. Main effects were statistically significant for all measures except for feeling energized. As reported in Table 4, the achievement score (Figure 2.1) and feeling pride (Figure 2.1) were strongest in the achievement condition compared to all other conditions. Ratings for feeling inspiration were strongest in the achievement condition but did not differ significantly from the beauty facet. Being inspired, feeling admiration and respect did only differentiate achievement from amusement but not from affection or beauty. Finally, feeling energized did not differ significantly across the four conditions. As indicated earlier, we exploratorily repeated the contrast for the two achievement score items separately. In general, the results were comparable to the average score and also showed the highest rating in the achievement condition. The differences in contrast to the other conditions were generally stronger for the obstacle item.

For the beauty model, we also obtained an overall significant main effect, $F(3,427)=9.59, p<$ .001 , with all five dependent variables obtaining a significant main effect. Ratings of experiencing chills (Figure 2.1) and feeling awe (Figure 2.1) were most robust for beauty and differed significantly from all other categories. Ratings for the beauty appraisal were also highest for the beauty coding but did not differ significantly from affection and achievement (Figure 2.1). Similarly, goosebumps ratings were strongest for the beauty category but did not differ significantly from achievement. Finally, the motivation to reflect on the experience did not differ significantly from achievement and affection, though from amusement.

For the affection model, we observed an overall significant main effect, $F(3,427)=12.80, p<$ .001 , with all seven variables showing a significant main effect. First of all, the affection score (Figure 2.2) and the motivation to feel more committed to a relationship were, as predicted, highest in the affection condition in comparison with achievement, beauty, and amusement. Similarly, feeling heart-warmed, touched, (Figure 2.2) and love were strongest for affection and differed significantly from the three other categories. A feeling of warmth in the chest was also rated most strongly for affection but only differed significantly from beauty and amusement. Finally, feeling moved was strongest for the affection category but not significantly different from beauty as in Study 2.

For the amusement model, we also observed an overall main effect, $F(3,427)=15.05, p<.001$, with all models except for the one testing buoyancy showing a significant main effect. All ratings except 
for the item on buoyancy were most robust in the amusement condition in comparison with achievement, beauty, and affection (see Table 4 and Figure 2.2).

As registered, we also explored whether the type of social context (alone vs. together with others) differed across the four tear types by performing a Chi-square test. The resulting test was significant, $\chi^{2}(3)$ $=14.33, p=.002, \varphi=.18$, though its effect size was rather small. Amusement tears were reported to occur most frequently together with others $(91.67 \%)$, while the other three categories showed a relatively smaller but still high frequency for the occurrence with other individuals (achievement, 75.52\%; affection, 69.66\%; beauty, $68.42 \%)$.

We also performed additional analyses on the items using a principal component analysis (PCA) and a network analysis, which can be found in the Supplementary Materials (3.4-3.5). In general, the findings revealed that the four categories emerged at large, although the beauty and achievement types were overlapping to a high degree. In addition, feeling moved was identified as the most central item.

\section{Discussion}

The present study provided a confirmatory test of preliminary findings from Study 2. By directly manipulating the various types of positive tears, we intended to explore further and confirm the specific profiles of achievement, beauty, affection, and amusement tears. We have to acknowledge that our manipulation did not entirely work as intended. Coding the final episodes revealed that participants did not always report the category as instructed. Therefore, we decided to use our coding factor as a further way to distinguish across categories. Although not following the pre-registered criteria, we strongly feel that these analyses provide a more valid picture.

Importantly, we observed that the four different categories did not differ in the amount of positive valence they evoked. Thus, it seems that all categories evoke an equally strong degree of positive feelings. Simultaneously, we demonstrated that amusement tears feature the least amount of negative affect with all other categories evoking slightly higher levels. It is also noteworthy that all categories included a comparable amount of reported tears. While the affectionate category included the highest mean, this did not differ significantly across the other conditions. Therefore, it seems that the four positive tear types do not differ qualitatively with regard to experienced tears and positive valence. These findings replicate our observations from Study 2. 
There is one distinct finding with regard to the different tear types from this study. Considering most of the ratings, the principal components analysis, and the network graph, it is clear that amusement is most distinctive from the three remaining categories. Not only do all amusement items form a component and a cluster, but most ratings also show the largest effect sizes when contrasting amusement with one of the other categories. This is not surprising as previous research has pinpointed a conceptual difference among those categories (e.g., Algoe \& Haidt, 2009; Graham, Thomson, Nakamura, Brandt, \& Siegel, 2017). According to the present study, amusement tears include a highly distinct profile being elicited by highly amusing events possibly including aspects such as exaggeration or surprise, involving giggling or laughing, motivate joking, and including feelings of amusement or being entertained. They also seem to involve a feeling of lightness, though not exclusively.

In addition, as is obvious in the ratings, component, and network analysis, the affectionate category can be distinguished from the other categories. Affectionate tears are evoked by sudden increases in closeness or communality and motivate individuals to act communally and prosocially. They also include feelings of compassion, love, kama muta (Zickfeld et al, 2018), and possibly elevation (Haidt, 2003). Warm feelings in the center of the chest also constitute an important part, though not exclusively as they can also occur in the case of achievement or beauty tears.

Achievement tears also can be distinguished quite well from the other categories. Although our findings suggest some overlap with the beauty category, which we will discuss later, achievement tears are elicited by observing extraordinary performance, perceiving someone overcoming an obstacle, or attaining extraordinary performance oneself. They include feelings of pride. The category also features feelings of inspiration, though this did not differ significantly from the beauty category. Feelings of gratitude, admiration, and respect were also strong in the achievement category, though not significantly different from beauty or affection.

As mentioned earlier, we did not find as much evidence for the beauty category as expected. First, in the component analysis, most items loaded together with achievement or affection items. Similarly, in the network model, beauty items had strong associations with items from these two categories. We further failed to find evidence that beauty tears were significantly more experienced as perceiving beauty or greatness as well. First, this reflects the general picture that achievement, beauty, and affectionate tears share a high degree of overlap. For example, holding one's newborn for the first time after a long and 
complicated birth might result in shedding achievement, beauty, and affectionate tears. One could feel relieved and proud of the achievement, perceive the extraordinary beauty of the new life, and simultaneously feel the attachment and love to one's offspring. This overlap reflects the general tendency that emotions do not occur in isolation but rather as a multifaceted interaction of processes that sometimes result in a mélange of feelings (e.g., Lange \& Zickfeld, 2019). Such processes might be isolated in highly controlled laboratory experiments, but we think that our approach captures the actual occurrence and paints a more ecologically valid picture of the nature of positive tears. Second, we obtained evidence that beauty tears prominently include experiencing chills and feelings of awe, which distinguish this category from affection and achievement lending more support to the fact that this type should be included as a separate category. Beauty tears can also include feelings of inspiration or reflection when occurring due to greatness, which might also prompt achievement tears. Similarly, they can include more affectionate feelings in the case of, for example, music (e.g., Zickfeld, 2018).

The present study has generally confirmed our postulated framework of positive tears and has provided further support for individual categories by uncovering similarities and differences across them. In the next and final steps, we explore the general occurrence of these four categories and investigate how they differ across demographic variables such as gender or age, cultural variables, and how they are associated with individual differences.

\section{Study 4a: Individual Differences in Positive and Negative Tears}

The previous studies explored situational episodes of positive tears and derived a framework, which was confirmed in the last step. The three final studies focus on the individual differences of positive tears and general proneness to achievement, beauty, affectionate, and amusement tears. The first step (Study 4a) builds upon a previously published representative panel study of the general Dutch population (Denckla et al., 2014) and explores differences in gender, age, and other variables. The second step (Study 4b) consisted of a previously published rich cross-cultural dataset (Becht \& Vingerhoets, 2002; van Hemert et al., 2011) and explores differences in gender, age, and cross-country effects. The third step (Study 4c) more systematically targets specific individual difference measures, including the big five personality traits and empathy to show their relations to positive tears.

In Study $4 \mathrm{a}$ and $4 \mathrm{~b}$ our general focus was exploratory, therefore we randomly split the dataset into two halves: one train and one test dataset or more precisely one exploratory and one confirmatory dataset. 
First, we explored our analysis using the training dataset, setting our alpha level to .05. In order to confirm findings, we then re-tested with the test dataset setting the alpha level to .005 (see IJzerman et al., 2018; Lakens et al., 2018 for a discussion).

\section{Method}

Participants. For the first step, we made use of the dataset collected as part of the Longitudinal Internet Studies for the Social Sciences (LISS) panel. This panel consists of a probability sample of Dutchspeaking households in the Netherlands and is representative of the Dutch population with respect to several variables. The data have been first published by Denckla and colleagues (2014), and an overview of sample characteristics is presented in their Table 1. We employed the sample from Time 1 reported in Denckla et al. $(\mathrm{n}=4916)$. Twelve participants showed no responses on the main variables, thus our final sample consisted of 4904 participants ( 2255 men, 1 missing) ranging from 16 to 97 years of age $(M=$ $50.14, S D=17.38)$.

Procedure \& Materials. Next to measures presented in Denckla and colleagues (2014), participants completed 28 items of the Crying Proneness Scale. These describe different situations that possibly elicit tears (e.g., "Someone dying", "A wedding ceremony") in individuals, and participants are asked to provide how likely they would cry in the given situation on a 7-point scale from very unlikely (1) to very likely (7). An overview of all 28 items is presented in the Supplementary Material 4a.1.

For the current purpose, we divided these items into positive and negative tear eliciting situations. As the scale did not contain all possible scenarios of shedding tears (e.g., amusing tears), we were not able to divide the items into the four subcategories. Items were categorized based on a pilot study including 30 UK participants who rated the valence of each item (see Supplementary Materials 4a.2). Each proneness rating was thus categorized as either positive or negative. The item 'When you see how good the world is, and that people help each other selflessly (altruistically, i.e., without expecting something in return)' was not completed by any participant and thus removed from the final analyses. The items 'People that say goodbye, leave each other, moment of departure', 'When someone experiences a rejection or loss (not win; also in a sporting event)', and 'If you see something almighty, huge, and beyond understanding' were also removed as the Pilot Study did not clearly identify them as either negative or positive, thus leaving 24 items for the final analyses (of which 14 were identified as positive and 10 as negative).

\section{Results}


For each participant we calculated a positive score averaging ratings for the 14 positive items and a negative score averaging the ten negative items. As each participant had two proneness scores (leaving a total number of 9808 observations), we employed multilevel models using the lme4 package in R. We randomly split the dataset in half to create a train (4875 observations) and test dataset (4933 observations). Our first main model included the proneness rating (how likely one would cry) as the dependent variable, the type of tears (positive vs. negative), and gender as predictors, as well as age in years as a covariate. In addition, we included all possible two- and three-way interactions. Intercepts were allowed to vary randomly according to participants.

Gender differences. In the training dataset we observed significant effects (at the .05 level) for type, gender, age, the two-way interactions between gender and type, gender and age, and the three-way interaction among type, gender, and age. In the test dataset we confirmed the effect on type, gender, age, the two-way interaction between type and gender, and gender and age but not the three-way interaction (at the .005 level; see Supplementary Table 5). In the following we focus on the aggregate of the total dataset. For the full dataset, we observed significant main effects for gender, $F(1,4899)=119.10, p<.001$, as well as for the interaction with type, $F(1,4899)=46.27, p<.001$. Women provided overall higher proneness ratings $(M=3.64, S E=.02)$ than men $(M=2.85, S E=.02)$. This gender difference was smaller for positive $(d=.48[.43, .54])$ than negative tears $(d=.73[.68, .79])$. In addition, differences within men between proneness to negative $(M=2.98, S D=1.26)$ and positive tears $(M=2.78, S D=1.25, d=.15[.10$, .21]) were smaller than differences between negative $(M=3.88, S D=1.21)$ and positive $(M=3.37, S D=$ $1.19, d=.43[.37, .48])$ for women.

Age effects. We also observed a main effect of age, $F(1,4899)=292.98, p<.001$, and an interaction effect with type, $F(1,4899)=23.29, p<.001$. In general, proneness to tears increased with age. However, this effect was slightly stronger for positive tears $(r=.21[.19, .25])$ than negative tears $(r=.16$ $[.14, .19])$. Inspecting the non-linear relationship suggested that both tears first increase gradually with age, although positive ones do so more strongly until they reach a plateau at about 60 to 75 years when they decrease again. We did not observe a significant type by gender by age interaction, suggesting that the male and female pattern were mostly similar.

We also inspected differences in negative and positive tears for net income, relationship status, number of children, household arrangement, and attachment style. We observed that the difference in 
proneness for negative and positive tears decreased with higher income. The detailed results are presented in the Supplementary Material 4a.3.

\section{Study 4b: Cross-cultural Differences in Positive Tears}

In Study 4a, we explored gender and age differences using a representative national panel. We now turn to cross-cultural differences among the four different positive tears and specific differences in the quality of positive and negative tears.

\section{Method}

Participants. For this second step, we made use of the dataset from the International Study on Adult Crying (ISAC; Becht \& Vingerhoets, 2002), which includes a total of 5715 participants (3218 women) from 37 countries ranging from 16 to 74 years of age $(M=23.37, S D=6.98)$. The majority of participants (86.5\%) were students. Specific information on recruitment is provided in Becht and Vingerhoets (2002). The dataset is one of the first and few systematic cross-cultural investigations of adult crying and collected data from all populated continents. The following regions were included in the dataset: Africa $(N=3)$, Asia $(N=6)$, Caribbean $(N=1)$, Europe $(N=18)$, Middle East $(N=2)$, North America $(N=1)$, Oceania $(N=2)$, and South America $(N=4)$. An overview of all countries separately is provided in Table 5.

Procedure \& Materials. The study employed the Adult Crying Inventory (ACI), a self-report questionnaire including more than 100 items in five different parts. Part A investigates crying proneness with regard to 55 positive and negative situations and feelings. All items are rated on a 7-point scale from 1 (never) to 7 (always). Part B includes 24 items targeting the general functions of crying (e.g., "Crying helps me to deal with my problems") completed on a 7-point scale from 1 (do not agree) to 7 (agree). Part C asks about factors that influence the shedding of tears (e.g., "my personality") and is completed on a 6point scale from 0 (not at all) to 5 (very much). Part D instructs participants to describe their most recent crying episode and to complete several items with regard to recency, social context, and emotions involved. Finally, Part E includes questions related to crying within one's menstrual cycle.

For the current purpose, we mostly relied on items from Part A and D. Based on theoretical importance and factor analytic findings (Scheirs \& Sijtsma, 2001), we picked two items from the 55 items of Part A to represent each of the four different types of positive crying. For achievement, we used "I cry 
when watching or hearing an admired person" and "I cry when I have achieved success" $(\alpha=.58) .{ }^{7}$ For beauty, we included "I can be moved to tears by the beauty of natural scenes," and "I cry in response to the beauty of arts (music, literature, visual arts)" ( $\alpha=.64)$. For affection, we used "I cry when someone does something very special to me or someone else," and "I cry when I am reuniting with friends or family members" ( $\alpha=.57)$. For amusement, we picked the only item available "I sometimes laugh so hard that I start to cry." In addition, we averaged all seven items into a positive tears index $(\alpha=.74)$. Similarly, based on findings by Scheirs and Sijtsma (2001), we picked eight items from the total item pool to represent negative tears $(\alpha=.84)$. Of these items assessing negative crying, we included four items related to sadness (e.g., I cry at funerals) and four items related to distress (e.g., I cry when things don't go as I want them to go; see Supplementary Material 4a.1).

Part D first instructed participants to describe their most recent crying episode. They then completed items on how long ago and how long this episode took. Questions also targeted the intensity of the crying episode, how much time passed between the confrontation and the crying response, the place, and the exact time of the day the episode took place. Then, participants reported how many other people and what kind of people were present, and who or what was considered responsible for the crying episode. Moreover, participants were asked to indicate out of 17 emotion items which feelings they experienced. They also reported whether the crying episode changed a relationship or aspects of the situation, how the people present reacted, and whether their mental and physical state improved or worsened. A more detailed account of the measures is presented in the Supplementary Material (4b.1).

\section{Results}

An overview of descriptives for the four positive tears scores, the overall positive and negative tears scores for each country separately is provided in Table 5. As in Study 4a, we randomly split the dataset into two halves: one train $(n=2857)$ and one test $(n=2858)$ dataset or more precisely one exploratory and one confirmatory dataset. After performing analyses on the train and test datasets, we ran meta-analyses on the effects representing individual country effects separately on the whole dataset.

\footnotetext{
${ }^{7}$ Note that the rather low values of internal consistency are not a particular issue in the present context. On the one hand, scales with low internal consistency are found to have higher validity (Brennan, 2001), on the other hand, our items consist of a broad range of scenarios, so it is not surprising that there is no perfect internal consistency.
} 
First, we tested the fit of our positive tears measurement model, including achievement, beauty, and affection with two items each and amusement with one item. In general, the model fit was acceptable for the whole dataset $(\mathrm{CFI}=.98, \mathrm{RMSEA}=.06$ [90\%: $.05, .07]$, SRMR $=.02)$. When testing for measurement invariance across all countries (except for Germany, Italy, and New Zealand as they included no information on the amusement item) fit for the metric model was still acceptable $(\mathrm{CFI}=.95$, RMSEA $=$ $.08)$ but deteriorated for the scalar model $(\mathrm{CFI}=.85$, RMSEA $=.12)$ suggesting partial measurement equivalence (Byrne, Shavelson, \& Muthén, 1989).

We then tested for gender differences across the four positive tear types. In a repeated-measures ANOVA, we employed the four positive tear types (achievement, beauty, affection, amusement) as repeated measures and gender as a between-subject factor. Results on the training dataset revealed a significant within-subjects effect of tear type, $F(2,5694)=667.70, p<.001, \eta_{p}{ }^{2}=.20$, and an interaction of tear type and gender, $F(2,5694)=10.44, p<.001, \eta_{p}{ }^{2}=.004$. We also observed a main effect of gender, $F(1,2699)=230.54, p<.001, \eta_{p}{ }^{2}=.079$. Confirming our findings on the test dataset revealed nearly identical effects with the within effect, $F(2,5829)=692.31, p<.001, \eta_{p}{ }^{2}=.20$, the between effect, $F(1$, $2709)=207.10, p<.001, \eta_{p}{ }^{2}=.071$, and the within-between interaction, $F(2,5829)=12.34, p<.001, \eta_{p}{ }^{2}$ $=.005$, reaching statistical significance. Meta-analyzing the main gender effect for positive tears revealed stronger ratings for women $(M=2.62, S D=1.04)$ than for men $(M=2.06, S D=.93$, Cohen's $d=.57$ [95\% CI: .48, .65], see Supplementary Figure 4.1). Similarly, the within effect for different tear types was characterized by amusement showing the strongest potential to elicit tears followed by affection, beauty, and achievement (see Table 5). Amusement, thereby, differed significantly from all other three categories (Affection: $d=.61[.45, .77]$; Beauty: $d=.79$ [.65, .92]; Achievement: $d=.92[.71,1.13]$ ), affection from beauty $(d=.20[.09, .32])$ and achievement $(d=.40[.30, .49])$ and finally beauty from achievement $(d=$ $.17[.04, .31])$. This pattern was observable across the majority of countries. However, in Indonesia, Japan, Malaysia, Nepal, Romania, and Turkey, amusement tears seem to play a minor role with affectionate and achievement situations being sronger triggers. Beauty tears also played a more important role in European or more industrialized countries.

The within-between interaction was characterized by affection showing the largest gender differences $(d=.59[.50, .69])$ with women scoring higher on the scale, while these differences were less 
articulated for achievement $(d=.41[.34, .49])$, beauty $(d=.32[.26, .39])$ and particularly amusement $(d=$ $.26[.18, .34])$. Notably, a gender effect was considerably stronger for negative tears $(d=1.30[1.16,1.45])$.

Cross-cultural differences. Next, we explored the relationships of the four different categories with several country-level indicators. A detailed account of our analyses is presented in the Supplementary Material (4a.2). We employed a machine learning technique called random forests (Breiman, 2001), to identify the most important predictors of each positive tear category. Across the train and test dataset, we found that achievement and affectionate tears were most strongly associated with country-level indicators of gender inequality and distance from the equator. On the other hand, beauty and amusement tears were best predicted by individualism and level of human rights at the country level (see Supplementary Material $4 \mathrm{a} .2$, for a detailed treatise).

Differences Between Negative and Positive Tears. We also analyzed data from Part D of the ACI that asked participants to describe a recent crying episode and complete several questions with regard to that episode. Unfortunately, we were not able to distinguish among the four different positive tear categories as the dataset did not contain enough information. Thus, we focused on the overall difference between negative and positive tears. As participants did not indicate the valence of the episode, we employed an indirect way to distinguish between episodes. Participants completed an item asking whether specific emotions were experienced. This list contained 17 different emotions. Using a parallel analysis of these items, we identified three components. The first component contained positive emotions (relief, joy, satisfaction, elation, being touched, and rapture), the second component contained more sad and fearful emotions (sadness, fear, (self) pity, powerlessness, guilt, frustration, and dismay), and the third component contained more anger directed emotions (contempt, humiliation anger, disgust). As the last two components correlated substantially $(r=.43[.37, .46])$ we combined them as the negative component. Next, we created a factor coding for whether participants experienced only negative emotions, only positive emotions, or a mixture of both. In total, 3373 (59\%) of participants reported negative tears, 648 (11.3\%) positive tears, $1546(27.1 \%)$ mixed tears, and $2.59 \%$ of cases were missing. In the present manuscript, we will not focus on mixed tears. The distribution of the type of tears differed across gender, $\chi^{2}(2)=108.42, p<.001, v=.14$. Women reported more often only negative emotions during the last crying episode (60.7\%), while men reported more often only positive emotions (61.3\%). 
We then compared and investigated differences between negative and positive tear episodes with regard to the time of the last crying episode, the duration, the intensity, the time of the day the episode occurred, the number of people present, mental and physical health after the episode, and relationship or situation changes. For each variable, we ran a multilevel model with the coding of episode type as the predictor. Intercepts were allowed to vary randomly according to subjects nested in country. We first performed the model on the training dataset and then confirmed our findings using the test dataset. As both datasets showed by and large similar effects, we report the analyses conducted on the whole dataset. An overview of the results is presented in Table 6 . We observed no difference between the time of the last crying episode, suggesting that negative tear episodes occur as frequent as positive episodes. We observed a stronger effect for the negative episodes for the duration, intensity, and time passed between the antecedent and the crying episode. Negative episodes were longer in duration, more intense, and also longer postponed, possibly reflecting the fact that individuals prefer to shed negative tears alone. On the other hand, we found a positive effect for positive episodes for the time of the day, number of people present, mental and physical health after the crying episode, as well as, relationship and situation changes. Positive episodes occurred slightly later during the day, though this difference was minimal and not consistent for the train and test datasets. Positive episodes also included a higher number of people present. Moreover, participants reported more improved mental and physical states after a positive crying episode than after a negative one. We also found a small effect that a relationship involved in the crying episode improved more following a positive than a negative episode. Though again, this effect was not consistently observed across both datasets. Finally, we also found that participants reported an improvement in the general situation for positive tears.

We also explored differences in antecedents, place of the episodes, and who or what was responsible for the crying episode. For antecedents, we found, not surprisingly, that positive episodes were more often characterized as positive, while negative included conflict or loss, validating our distinction. We observed no systematic differences in the place where the episodes occurred. Finally, regarding responsibility, we found that oneself, a partner, and family/relatives were slightly more often responsible for negative episodes than for positive ones. On the other hand, the episode types did not differ on what type of people were present. Only strangers were more often reported for positive episodes.

\section{Discussion}


Across 37 diverse countries, we explored the general proneness to different types of positive tears. We measured positive tears based on an existing scale targeting the general occurrence of tears (Scheirs \& Sijtsma, 2001), and our solution showed an acceptable model fit. Contrary to the results of Studies 2 and 3, which asked directly about an episode of positive tears, the pattern of the frequency was rather different. While participants in our previous studies reported most frequently episodes containing affectionate or achievement, participants in the present study indicated to be prone mostly to the amusement category that occurred substantially low in our previous coding. However, these findings do not rule out each other as amusement tears might occur most frequently and are therefore perceived as something more ordinary. When prompted to remember an episode of positive tears participants might not rely on such mundane experiences but rather remember significant emotional events such as weddings, the birth of a child or winning an important award that might not occur on a daily basis. Importantly, amusement was also not reported as the strongest trigger of tears across all countries. In some non-Western countries, participants indicated as being the least prone to shedding tears due to something amusing (see also Krys et al., 2016). This was also obvious in a supplemental analysis as country level individualism correlated positively with amusement tears. On the one hand, this finding might be explained by the fact that countries facing tougher economic situations or lower health care levels have few things to laugh about (Dolan, Peasgood, \& White, 2008), on the other hand, this could also be a pattern influenced by specific cultural norms. In the countries that showed lower proneness to amusement tears, affectionate or achievement tears seemed to be more important than in the rest of the sample possibly reflecting a specific cultural pattern or the influence of other factors such as religiosity.

Replicating previous findings, we observed a generally stronger proneness of women to report positive tears on a whole and also its four subtypes than male participants in Study 4a and 4b (van Hemert et al., 2011; Zickfeld et al., 2018). These findings are not necessarily in contrast to previous evidence suggesting that men are more likely to shed positive tears than women (Vingerhoets \& Becht, 1997; Williams \& Morris, 1996). However, the difference between women and men was much stronger for negative than for positive tears in Study $4 \mathrm{a}$ and $4 \mathrm{~b}$. Within the positive tears, affectionate tears showed the largest gender difference possibly driven by differences in empathy and compassion (Schieman \& Van Gundy, 2000). 
We also found evidence that proneness to positive tears was more strongly associated with biological age supporting the notion that positive reasons for emotional crying become more important at a more advanced age (Vingerhoets \& Bylsma, 2015). Yet, we did not find strong evidence that proneness to negative tears decreases with age as typically suggested as it also increased in Study 4a. In an additional analysis of Study $4 \mathrm{~b}$ (Supplemental 4b.2), we found that proneness to negative tears decreased with age, though the age range in this study was not as representative as in Study 4a. In the same study, we only found a small effect for beauty tears, which needs to be replicated across different contexts to assess its stability and replicability.

Focusing on the overall distinction between negative and positive tears, we also found some evidence that positive tears occur more often when other people are present, while negative tears occur more often when being alone or with fewer, and more intimate (e.g., romantic partner, mother, best friend), people present. These findings support the notion that positive tears are more social than negative ones as they more often occur in contexts where others are present. Positive tears probably support a more general bonding mechanism, while negative tears focus specifically on attachment to intimate others. Participants also reported better mental and physical states and felt that relationships and situations improved slightly more after shedding positive tears in comparison with negative tears. Negative tears, on the other hand, were experienced as more intense and longer in duration. Unfortunately, we were not able to test these effects for the four different categories. Thus, it remains to be shown whether positive tears, in general, not only differ qualitatively from negative tears but also each of the different positive categories.

Finally, different types of positive tears were predicted by different country-level characteristics. Both beauty and amusement tears were reported as more likely in an individualistic context. In addition, beauty tears occurred more as more likely in countries showing higher ethnic and linguistic diversity and amusement in countries showing on average higher subjective well-being and levels of human rights. On the other hand, achievement and affectionate tears were associated with relatively low (gender) equality and a small distance from the equator. Thus, at first glance, it might seem that individuals in more industrialized and individualistic countries are more prone to amusement and beauty tears, while individuals in more communal and less-industrialized show higher proneness to achievement and affectionate tears. However, caution should be applied before drawing too firm conclusions from these findings. First, we included a rather low number and variation of different countries with most countries 
coming from a European context. The relationships might thereby be inflated by less represented regions such as Africa or South America. Second, there are many possible explanations why, for example, affectionate tears show higher proneness in countries with less (gender) equality. Communal themes might be more common in more religious countries that are often at the same time associated with less gender equality (Solt, Habel, \& Grant, 2011). The general conclusion that we can draw from this study is rather that proneness to the different types of positive tears differs across different regions and cultures. In the following and final study, we provide a further test of proneness to positive tears and different cultural, biological, and psychological variables.

\section{Study 4c: Individual Differences of Positive Tears}

The main aim of the final study was to investigate the proneness for positive tears and to explore individual differences with regard to personality, including the Big 5 personality traits and empathy. A vast literature of personality traits can be drawn on to examine the link with the different positive tear types. In previous studies, crying has been associated with high neuroticism (De Fruyt, 1997; Peter, Vingerhoets, \& Heck, 2001), though these studies focused on negative crying primarily. Regarding other Big 5 factors, research on pride and achievement have related this state to extraversion and, to a lower degree, agreeableness (Tracy \& Robins, 2007; Tracy, Shariff, \& Cheng, 2010). Further, aesthetics such as visual arts and experiences such as goosebumps have been linked to openness to experiences (Colver \& ElAlayli, 2015; McCrae, 2007; Silvia, Fayn, Nusbaum, \& Beaty, 2015). In addition, affectionate and communal experiences such as compassion have been associated with agreeableness and also empathy (Goetz, Keltner, \& Simon-Thomas, 2010). Finally, amusement and sense of humor have been consistently related to extraversion (Mendiburo-Seguel, Páez, \& Martínez-Sánchez, 2015).

In order to provide cross-cultural validity, we again sampled across several countries: the US, Norway, and Serbia. These countries differ quite substantially on various cross-country indices (see Supplementary Material 4c.2), making them adequate cases to test the robustness of our hypotheses. Based on our findings from the present studies and previous theoretical and empirical research, we derived the following hypotheses: (1) achievement, affectionate, and amusement tears are more often experienced together with others, while beauty tears are mostly experienced alone, (2) proneness to different kinds of positive tears are predicted by different personality variables: achievement and amusement tears are best predicted by extraversion, beauty tears by openness to experience, and affection tears by agreeableness, (3) 
the general proneness to positive tears is positively predicted by individual differences in empathy, (4) as observed in Study $4 \mathrm{a}$ and $4 \mathrm{~b}$, women report a stronger proneness for positive tears than men though this effect is not as large as for negative tears, and (5) proneness to positive tears increases with age, while this relationship is reduced for negative tears.

\section{Method}

Participants. In total, we recruited 842 participants. Participants were excluded if they provided more than $50 \%$ missing responses based on pre-registered criteria. ${ }^{8}$ US participants were recruited on Amazon MTurk, while Norwegian and Serbian participants were recruited through snowball sampling and on social media. The Serbian sample also consisted of a number of participants from other countries, which we subsume under the label other. The final sample consisted of 752 participants (414 women, 320 men, 18 missings) from which 200 were of Norwegian, 271 of US, and 187 of Serbian nationality. An additional 94 participants indicated another nationality. ${ }^{9}$ Ages ranged from 16 to $72(M=32.53, S D=$ 10.88). ${ }^{10}$

Procedure \& Materials. The present study featured a correlational design. After receiving informed consent, participants received a subset of the 54-item proneness section of the Adult Crying Inventory (Vingerhoets \& Cornelius, 2001). We chose the same 16 items as in Study $4 \mathrm{~b}$ to represent items referring to positive and negative crying proneness. Of the 8 items measuring positive crying we included each two items targeting achievement (e.g., "I cry when I have achieved success"), beauty (e.g., "I cry in response to the beauty of arts (music, literature, visual arts)"), affectionate (e.g., "I cry when I am reuniting with family members or friends"), and amusement tears (e.g., I sometimes laugh so hard that I start crying). The original scale featured only one item assessing amusement, so we added an additional item ("I cry when I observe or experience something really funny"). Of the eight items assessing negative crying, we included four items related to sadness (e.g., "I cry at funerals") and four items related to distress (e.g.,

\footnotetext{
${ }^{8}$ Note that the pre-registration was drafted based on a class group project with a different focus. Although the pre-registered hypothesis and analysis plan are not of interest for the present study, the pre-registered criteria with regard to exclusion or sample size determination are adapted.

${ }^{9}$ Nationalities included under this label were scattered across 31 countries, but frequencies were not high enough to allow a creation of an own category (e.g., 11 participants indicated Croatian nationality and 17 Montenegrin). Importantly, Croats and Montenegrins speak the same language (Serbo-Croatian) as Serbs, though different dialects. Still, we decided not to merge these and differentiate between Serbia and other. ${ }^{10} \mathrm{~A}$ pre-registered power analysis was conducted with the focus on a different research question not analyzed in the present manuscript, resulting in a final sample size suggestion of 300 participants. Considering literature on when correlation coefficients stabilize, we deem our final sample size of 752 participants appropriate for the present context (Schönbrodt \& Perugini, 2013).
} 
"I cry when things don't go as I want them to go"). All items were completed on a scale from 1 (never) to 7 (always). For each of the 16 items, the participants also indicated whether they experienced the specific type of tears more often alone or together with other individuals using a dichotomous response format.

Subsequently, participants completed the BFI-20 (Engvik \& Clausen, 2011), a 20 item scale assessing the Big 5 constructs on a scale from 1 (strongly disagree) to 7 (strongly agree). In addition, participants were presented with the 20-items Basic Empathy Scale (Jolliffe \& Farrington, 2006) measuring both a general tendency of empathy and its cognitive and affective components. The measure was completed on a 5-point scale from 1 (strongly disagree) to 5 (strongly agree). Items from both measures were presented in randomized order.

Additional measures not focal to the present research question are presented in the Supplementary Material (4c.1). Finally, participants reported demographic information including gender, age, number of children, and nationality.

\section{Results}

First, we created a sum score of all eight positive $(\alpha=.85)$ and all eight negative crying proneness items $(\alpha=.87)$. In addition, of the eight positive items we created an index for achievement $(\alpha=.69)$, beauty ( $\alpha=.75)$, affection $(\alpha=.73)$, and amusement $(\alpha=.81)$ tears with two items each. We repeated the same step for the questions concerning social setting by combining them to a score about the setting of positive, negative, or the four distinct positive types. These final scores ranged between 1 (alone) and 2 (together). As in Study 4b, the measurement model including the four different positive tear types showed an acceptable model fit $(\mathrm{CFI}=.99, \mathrm{RMSEA}=.05[90 \%: .03, .07]$, SRMR $=.02)$ and we also observed metric invariance across the three countries $\left(\mathrm{CFI}=.99, \mathrm{RMSEA}=.05, \chi^{2}\right.$ diff $\left.(8)=20.74, p=.008\right)$, while the fit was worse for the scalar model $\left(\mathrm{CFI}=.95, \mathrm{RMSEA}=.09, \chi^{2}{ }_{\text {diff }}(8)=96.01, p<.001\right)$.

First, we tested for gender differences across the four positive tear types. In a repeated-measures ANOVA, we employed the four positive tear types (achievement, beauty, affection, amusement) as repeated measures and gender as a between-subjects factor. Results replicated the previous study findings revealing a significant within-subjects effect of tear type, $F(2.66,1942)=70.42, p<.001, \eta_{p}{ }^{2}=.09$, and an interaction of tear type and gender, $F(2.66,1942)=12.03, p<.001, \eta_{p}{ }^{2}=.011$. We also observed a main effect of gender, $F(1,511)=91.20, p<.001, \eta_{p}{ }^{2}=.11$. Meta-analyzing the main gender effect for positive 
tears revealed stronger ratings for women $(M=3.23, S D=1.18)$ than for men $(M=2.38, S D=1.19$, Cohen's $d=.72$ [95\% CI: .57, .88], see Supplementary Figure 3.2). Similarly, the within effect for different tear types was characterized by amusement being reported as the strongest trigger followed by affection, achievement, and beauty. As in the previous study, amusement differed significantly from beauty and achievement, but not from affection (affection: $d=.21[.00, .41]$; achievement: $d=.42$ [.18, $.66]$; beauty: $d=.52[.27, .78])$, affection from beauty $(d=.32[.22, .42])$ and achievement $(d=.22[.12$, $.32])$, and, finally, contrary to the previous study beauty not from achievement $(d=-.11[-.26, .11])$.

The within-between interaction was characterized again by affection showing the strongest gender differences $(d=.79[.64, .94])$ with women scoring higher, while these differences were less articulated for achievement $(d=.53[.38, .68])$, beauty $(d=.41[.26, .56])$, and amusement $(d=.50[.35, .66])$.

Heterogeneity for these effects was generally low with all three countries showing comparable effects. As in the previous study, the gender effect was considerably stronger for negative tears $(d=1.47[1.18,1.76])$ than for positive tears overall $(d=.72[.57, .88])$.

Second, as in the previous step, we tested the relationship between participant's reported age and trigger power of the the negative and (different types of) positive situations. In the present studies, affection $(r=.10[.03, .17])$ showed a positive significant relationship. All other categories showed no significant relationship: achievement $(r=.07[-.04, .17])$, beauty $(r=.06[-.03, .14])$, amusement $(r=-.01$ $[-.08, .06])$. Similarly, negative $(r=-.07[-.14, .00])$ and positive $(r=.07[-.01, .15])$ overall tears showed no significant relationships, though they suggested a possible interaction with the occurrence of positive tears increasing with age, while negative tears decrease, $F(1,730)=21.58, p<.001$.

To test whether social settings differed across the four main categories, we ran a repeated measures ANOVA with the setting scores (0: alone, - 1: together with others) for each category as repeated scores. We also added gender as a between subject factor. The analysis revealed a main effect for gender, $F(1,671)=59.48, p<.001, \eta_{p}{ }^{2}=.08$, with women $(M=1.49, S E=.01)$ more frequently reporting tears together with others than men $(M=1.32, S E=.02)$. In addition, we observed a main within effect for tear category, $F(2.8,1906)=341.79, p<.001, \eta_{p}{ }^{2}=.34$, with amusement tears most often shed together with others followed by affection, achievement, and beauty. Amusement, thereby, differed significantly from all three other categories (affection: $d=.37[.18, .57]$, achievement: $d=.84[.72, .96]$, beauty: $d=$ $1.34[1.03,1.65])$, while affection differed from both achievement $(d=.45[.33, .58])$ and beauty $(d=.91$ 
$[.76,1.06])$, and achievement from beauty $(d=.45[.30, .60])$. We also observed a within-between interaction with gender, $F(2.8,1906)=15.92, p<.001, \eta_{p}^{2}=.02$. While women, on average, provided more frequent accounts of shedding tears in a social setting, this difference was not observed for beauty tears. Finally, positive tears in general were reported as being shed together with others more frequently than negative tears $(d=.76[.59, .94])$. Differences across samples were in general quite homogenic. The US effects showed most often differences from the Norwegian and Serbian ones.

In the next step, we explored the relationship between each positive tear category, and the Big 5 personality traits (see Table 7). For the achievement model, we found significant positive associations for extraversion, agreeableness, and neuroticism. Extraversion showed the strongest effect when controlling for the other predictors, though it was smaller in the Norwegian sample. For the beauty model, we observed a significant positive prediction by openness to experience and neuroticism. Openness showed the most potent effect across all countries when controlling for all other predictors, though the effect was rather heterogenous. In the US sample, the effect was relatively small in comparison to the Serbian sample. For the affection model, we observed significant positive predictions by extraversion, agreeableness, and neuroticism. Agreeableness showed the most substantial effect across all countries when controlling for the other predictors. The effect was strongest in the US and smaller in the Norwegian sample. For the amusement model, we found significant positive predictions by extraversion, openness, and a negative one by conscientiousness. Extraversion showed the most robust effect with the Serbian effect being the smallest.

Finally, we examined the association between trait empathy and the four different tear types. Across all samples, all types correlated positively with empathy with affection showing the strongest association $(r=.35[.29, .41])$, while the others were somewhat lower: achievement $(r=.22[.16, .29])$, beauty $(r=.20[.13, .26])$, and amusement $(r=.23[.17, .30])$. When regressing all types on empathy only affection and amusement showed a significant positive effect. Affection was the strongest predictor $(r=$ $.33[.24, .43])$ when controlling for all other types.

\section{Discussion}

In the final study, we aimed at replicating previous findings with regard to general crying proneness, gender, and age as well as further exploration of individual differences in positive tears across three different countries. First, we replicated previous findings that women reported, on average, a higher 
proneness to positive tears. Again, this difference was strongest for the affectionate category and smallest for beauty and amusement. Similarly, though, the gender difference was smaller for positive than for negative tears. This finding might be explained by differences in gender roles and norms. While crying due to negative reasons such as pain and helplessness might signal weakness, this could be less so for positive reasons such as achievement or beauty (Williams \& Morris, 1996). However, it should be noted that the general appropriateness might be also high for men crying at a funeral (Rosenblatt, Walsh, \& Jackson, 1976; van Hemert et al., 2011). For the relationship with biological age, we found a positive relationship with proneness to affectionate tears, which was not found in the previous study. Generally, we replicated findings in Study $4 \mathrm{~b}$ that proneness to negative tears decreases with age, though not statistically significant in the present study. In Study 4a, we also observed that proneness to negative tears increased with age. On the other hand, the question if positive tears, and exactly what type of tears, increase with age, needs more empirical attention. The present studies provided evidence for a positive relationship of age with beauty and affection tears, though not consistently. In addition, we found that, against common theorizations (Vingerhoets \& Bylsma, 2015), neuroticism is not the primary personality factor affecting proneness to emotional crying, at least not when it is positive. Achievement and amusement tears were most strongly predicted by extraversion, beauty by openness to experience (Colver \& El-Alayli, 2015; McCrae, 2007; Silvia et al., 2015), and affection by agreeableness when controlling for the other personality types. While types also showed a positive relationship with neuroticism, this was by far not the strongest one. Finally, we replicated findings from Study 2 and 4b, showing that positive tears are social tears in comparison to their negative counterparts. Amusement tears were most often reported to be shed together with other individuals, including strangers, whereas beauty tears were reported the least social with affection and achievement somewhere in between. Not surprisingly, proneness to affectionate tears was also found to be strongest associated with trait empathy (Zickfeld et al., 2017). This fits the parallel finding that they are also mostly predicted by agreeableness and highlights the general empathic and compassionate nature of that tear type. While the results of this study replicated previous findings to a certain extent, we also observed some remarkable differences across our samples. We cannot definitely say whether these differences are informed by cultural factors, linguistic properties of our items, or that they occurred due to chance. What is most important is that they fit the general picture obtained across our present studies and in previous studies (Damen, 1999; Landmann, Cova, \& Hess, 2019; Strick \& Van Soolingen, 2017; 
Vingerhoets, 2013). Just like as it is the case for negative tears, the occurrence of positive tears is also most likely a complex interplay of biological, social, psychological and cultural factors, but with different weights of the contributing factors. We will turn to a more detailed discussion in the next section.

\section{General Discussion}

Do positive tears exist, and how are they different from negative crying? Are there different categories of positive weeping and to what degree do they differ? In the present project, we provided a first systematic investigation of a taxonomic model of positive emotional crying. For this purpose, we collected data from 13124 individuals scattered across 40 different countries, six different continents, and 24 different languages. We coded more than 1500 individual episodes from participants across ten countries. Our investigation focused on whether there are positive tears, how they differ from each other, what kind of emotional states they involve, and whether there are social, cultural or psychological factors influencing the occurrence or proneness to positive tears. Our findings suggest that positive tears constitute a ubiquitous phenomenon across different cultures, and they are qualitatively different from negative emotional tears occurring due to sadness, despair, anger, or helplessness. In addition, we identified four distinct categories of positive tears labeled achievement, beauty, affection, and amusement. These categories were able to account for all episodes analyzed in the current manuscript and suggest that there might be different mechanisms for each of these categories. We will now first turn to a general discussion of positive tears and subsequently take a closer look at each of the four subtypes. Finally, we will place the taxonomic model in a broader context, discuss the limitations of our current work, and suggest future plans to investigate positive tears further.

\section{Positive Tears}

Nearly all of our participants were able to report an episode of positive emotional crying when prompted to do so. This is by itself an important finding as it supports the notion that there exist emotional tears that are not primarily negative (at least linguistically) and that occur at least so often and are so salient that people are able to remember them in retrospect. While previous findings suggested that men experience positive tears more often than women (Williams \& Morris, 1996), we were not able to find consistent evidence for this prediction. Although we found evidence in Study $4 \mathrm{~b}$ that men reported only positive tears more often than women did, in our final studies $(4 a-4 c)$, we rather found support for the opposite pattern, which fits previous (cross-cultural) investigations (Peter et al., 2001; van Hemert et al., 2011). However, 
this finding could also be influenced by the fact that male and female participants used and interpreted the rating scales differently. What we can conclude is that gender differences are smaller for positive tears than for negative emotional tears. This might be driven by the fact that negative tears are associated with decreased dominance and competence threatening traditional gender roles, while this mechanism is less pronounced for positive tears (Zickfeld, van de Ven, Schubert, \& Vingerhoets, 2018). Thus, while for men the experience and shedding emotional tears in a negative context might signal increased weakness or loss of control, showing positive tears could be interpreted as a sign of control and warmth (MacArthur \& Shields, 2015). As MacArthur and Shields argue, the prototype of masculinity (at least in the United States) does not consist of showing no emotion at all, but rather of controlling one's emotional reaction and showing passion. The possibility that positive tears are perceived as more controlled and passionate in contrast to more negative tears should receive attention in future studies.

We obtained only partial evidence that the prevalence of positive tears increases with biological age, as found in previous research (Vingerhoets \& Bylsma, 2015; Williams \& Morris, 1996). In Study 4a, proneness to positive tears increased with age and more so than proneness to negative tears. In Study $4 \mathrm{~b}$, we found a positive relationship with beauty tears and, in Study $4 \mathrm{c}$, with affectionate tears, though these findings were not consistent across studies. This might be based on a number of different reasons. The variance in age was rather low in studies $4 \mathrm{~b}$ and $4 \mathrm{c}$, which mainly included undergraduate participants. In order to obtain a more nuanced picture of this relationship, one would possibly need to study individuals below the age of 18 as well. Our findings suggest that the prevalence of positive tears increases with age, while there was no consistent pattern for negative tears. Future studies are needed to validate further whether an interaction between type of tears and gender exists.

Further, we found evidence that positive tears are inherently more social than negative emotional tears. In Study $4 \mathrm{~b}$ and $4 \mathrm{c}$, we observed that positive tears were reported to be shed more often together with other individuals present, while negative tears were less so. On the one hand, this might indicate that situations and elicitors of positive tears are more often social, which is why they occur more often together with other individuals. Indeed, except for the beauty category, all positive tear types included a high degree of social interactions in our studies (as also observed in Study 3). On the other hand, it could be that positive tears imply a social function signalizing, in particular also to strangers, affiliation and specific person characteristics and therefore they are more often shed in a social context than their negative 
counterparts, which seem to be shed specifically in the presence of (symbolic) attachment figures, such as best friends, romantic partners, parents, or god. Alternatively, it could be that positive tears signal that the cryer is a good person as (s)he attaches much value to important moral and societal values. Previous studies have linked emotional tears to fulfilling an attachment function (Murube et al., 1999; Zickfeld, Van de Ven, et al., 2018), though there is to date no evidence that this differs for different types of tears.

Finally, emotional tears have been typically linked to neuroticism. Individuals that are more emotionally unstable tend to shed more tears (De Fruyt, 1997). In Study 4c, we obtained evidence that this might be true for negative tears, but positive tears seem to be more strongly predicted by extraversion, agreeableness, and openness to experiences as we will discuss in more detail in the following sections.

We will now turn to an overview of the specific positive tear types. A summary, including tested and postulated aspects and mechanisms, is presented in Table 8 .

Achievement Tears. Achievement tears occur in response to an extraordinary performance or success, greatness, or overcoming an obstacle. Although these are subtypes of the category that might occur distinctively, overcoming an obstacle often involves a display of exceptional performance to overcome the obstacle in the first place. Examples of this category included individuals with extraordinary achievements in a school, work, or sports context, such as getting admitted to a prestigious study program, getting a promotion at work, or winning a prestigious championship. Similarly, the category included witnessing others with special achievements such as an underdog winning an important sports competition. Another frequently mentioned episode type involved regaining health after a long period of adversity. As indicated by our results, the category is rather social and often involves other individuals. Whether there are qualitative differences between shedding tears due to one's own achievement and observing the exceptional achievements of someone else was not the focus of the present investigation and needs more attention in future studies.

We identified feelings of warmth in the center of the chest and experiencing goosebumps, though none of these were distinct for this specific category. Goosebumps or blushing (possibly referring to warmth in the body) have been previously associated with feelings of achievement (Algoe \& Haidt, 2009; de Melo \& Gratch, 2009). Regarding motivation, the respondents reported feeling and being inspired by their own or other people's actions. Most frequently reported were feelings of pride, which has been argued to reflect a basic emotion (Tracy \& Robins, 2004), but also feelings of admiration and gratitude, though 
none of these two were distinct for the category. Interestingly, previous research has not specifically associated emotional tears as a display of pride (Tracy \& Robins, 2004) or admiration (Onu et al., 2016). Algoe and Haidt (2009) found evidence that participants feeling admiration reported emotional tears fitting the present findings and category. Finally, supporting previous findings, achievement tears were most strongly predicted by extraversion highlighting a possible social role of this category (Tracy \& Robins, 2007). Study $4 \mathrm{~b}$ also found that achievement tears were more prevalent in less industrialized countries.

Beauty Tears. Beauty tears occur in response to something aesthetically pleasing, especially beautiful objects, music, visual arts, or to a general state of perceiving life as good. Examples included individuals enjoying nature or the arts, such as listening to music or just feeling satisfied with one's life. In the previous studies we also included cute objects in this category as such agents might be perceived as especially beautiful. Importantly, cute agents have been linked with carefulness and tender feelings (e.g., Steinnes, Blomster, Seibt, Zickfeld, \& Fiske, 2019), thus they could possibly be considered part of the affectionate tears category. This proposition should be tested more systematically in future studies.

In both Study 3 and Study 4c, beauty tears were the least social positive tears. This can be easily accounted for by the fact that enjoying nature or the perception of art or music does not need the involvement of other individuals, though the presence of others might amplify the process. Remarkable is that we also found in Study 2 that beauty tears connect individuals to something larger than themselves such as nature or a general meaning-making process. Thus, while it might occur less often with other individuals present as found by our results, it still seems to be a rather social category connecting the crying individual to a greater good. Future studies need to test this proposition. In the present project, we showed that beauty tears are accompanied by chills and also goosebumps supporting the general literature on aesthetic chills (e.g., Bannister, 2018; Colver \& El-Alayli, 2015). We also found evidence for the occurrence of more deep breathing in contrast to the other categories. Beauty tears motivated reflective processes (Pelowski, 2015), though not distinctively for this category. Regarding feeling labels, in both Study 2 and 3, we observed the highest degree of feelings of awe in this category. The emotion of awe has been related to experiences of chills, as well as perceptions of vastness or greatness such as with nature or music (Keltner \& Haidt, 2003). However, there seems to be no research associating awe to emotional crying. Instead, feelings of being moved and touched were also rated high for the beauty tears. Such feelings have been related to emotional crying, and some authors have argued that the label of awe might 
be used for such being moved experiences (Fiske et al., 2017; Zickfeld, Schubert, Seibt, \& Fiske, 2018). Future studies need to further validate that the emotion of awe can be accompanied by emotional tears. Replicating previous research findings, beauty tears were strongly predicted by the trait specifically associated with aesthetic appreciation, i.e., openness to experience (McCrae, 2007; Silvia et al., 2015). Finally, beauty tears seem to occur more frequently in more individualistic countries.

Affectionate Tears. Affectionate tears highlight the occurrence of an intensification of communality or closeness and include situations such as unexpected kindness, sharing of emotional moments, or (unexpected) reunions. Individuals frequently reported episodes involving significant life events such as a wedding or birth to a child. Affectionate tears were found to be highly social and they also seem to motivate pro-social and affiliative intentions. These tears are most strongly predicted by empathy. These tears are accompanied by sensations of warmth in the body, although similar sensations were also reported in the case of achievement tears. Individuals feel moved, touched, compassionate, and also love. Affectionate tears are possibly most consistently related to the emotion of kama muta that is often accompanied by emotional tears (Fiske et al., 2017), and also related to compassion (Goetz et al., 2010). They can further be linked to the emotion of elevation, which highlights especially moral behavior (Haidt, 2003). Notably, though, moral behavior is not necessarily limited to the affectionate category and could also occur in the achievement category. Finally, affectionate tears were most strongly predicted by agreeableness, which also includes empathic and affectionate aspects.

Amusement Tears. Amusement tears were most consistently distinguished from the rest, possibly, because its mechanism is more distinct from the other categories, as we will discuss in more detail later. These tears were also rated as the most social, even stronger than the affectionate tears. Amusement tears are elicited by perceiving something funny, often based on aspects such as incongruity or surprise (Martin, 2007). It is accompanied by giggling, laughing, or wanting to joke with other people. While it seems to be the category that elicits the lowest level of pro-social or communal behavior, (the motivation of) sharing a laugh with other individuals is also an inherently social process (Keltner \& Bonanno, 1997). Further, as the label suggests, they are experienced as amusing and entertaining.

Interestingly, participants recollected the least episodes of amusement tears in Study 2 but indicated that the triggering power was highest for all categories in Study $4 \mathrm{a}$ and $4 \mathrm{~b}$, at least for more industrialized countries. Regarding the difference between recollection and reporting proneness, it is likely 
that amusement tears tend to occur to more mundane and frequent events, whereas the tears of the other categories are more strongly associated with emotionally important events, such as being admitted to a prestigious school, experiencing the spectacular fjords in Norway, or attending the wedding of one's own child. Thus, such situations are more salient and are therefore more easily recollected. Regarding the cultural difference, this could be explained by less favorable economic situations, which might affect subjective well-being (van Hemert et al., 2011), or cultural norms, which might moderate the display of amusement tears (e.g., Niedenthal, Rychlowska, Wood, \& Zhao, 2018). Finally, amusement tears were positively associated with extraversion possibly reflecting their social nature supporting previous findings (Mendiburo-Seguel et al., 2015).

The mechanism of positive tears. As discussed earlier, there are several theoretical explanations of why humans shed emotional tears. In the present project, we have uncovered different categories of positive tears, how they are elicited, and what emotional reactions they are accompanied by. However, we did not directly target to explore the general mechanisms that underlie emotional crying and whether they are distinct for negative and positive tears. Our findings suggest that (positive) tears act as a signal to facilitate bonding (Gračanin, Bylsma, \& Vingerhoets, 2017, 2018; Murube et al., 1999; Nelson, 2005). As Murube and colleagues speculated, positive tears might consist of the basic function to offer and request help. All categories excluding amusement tears showed high ratings of the intention to act communally, with the affectionate being strongest. Although beauty tears occurred the least frequently with other individuals present, it seems that they still include the tendency to offer help as ratings on motivation to approach another person were rather high in Study 2 and 3. Previous research targeting awe, the emotional response most salient in the beauty category, provided evidence that this feeling ignites a feeling of connectedness and increases pro-social behavior (Stellar et al., 2017). The mechanism for amusement tears might be somewhat more complex. First, in Study 3 and 4c, amusement tears were reported as most frequently occurring with other individuals present. Participants further reported the lowest ratings of wanting to act communally or offer help for this category. Thus, it is either possible that an alternative mechanism is involved here, or that amusement tears are indeed perceived as offering help. As an alternative explanation, amusement tears often (if not always) accompany intense laughter. It has been argued that laughter tears may simply result from the mechanical pressure put on the lacrimal gland by the contraction of the muscles around the eye when people laugh, maybe in a way similar to the effects of 
yawning and vomiting, which also may be accompanied by tears (Vingerhoets, 2013). While such an explanation would support the qualitative difference between amusement tears and the other categories, mechanical overstimulation could also be the reason for other categories when being overwhelmed and holding one's breath. In addition, we found evidence that amusement tears are accompanied by specific subjective feelings of amusement or feeling entertained. Thus, it seems to match our current definition of positive tears as emotional crying that is experienced as positively valenced. In general, the current set of studies supports the idea that a bonding function lies at the base of (positive) emotional crying although the actual mechanism that is in play warrants more detailed investigations also with regard to the different categories of tears. Importantly, also for future studies, it is crucial to investigate the difference between bursting out in laughter with and without tears or observing a great achievement with and without tears, to fully conceptualize the role of tears in these situations.

Another theorization has proposed that emotional crying is elicited by helplessness or being overwhelmed (Vingerhoets \& Bylsma, 2015) or that there is in the seeming positive situation always a negative aspect in the background, such as the suffering because one missed the other in case of a reunion, or the problematic and laborious recovery of an injury of an athlete winning a gold medal (cf. Feldman, 1957). Because, in the current study, we did not assess helplessness, conclusions are necessarily only based on indirect evidence. With regard to positive emotional crying, an overload of positive emotions could be construed as having trouble controlling them, resulting in feelings of helplessness and finally shedding tears. All categories include examples that are hard to control, and many episodes mentioned aspects of suddenness or unexpectedness, highlighting low control over the situation. Apart from that, future studies would need to rule out whether helplessness represents an essential factor in the occurrence of positive tears and whether it differs across distinct categories.

Finally, a recent review suggests that negative and positive emotional crying may be associated with different neural structures (Bylsma, Gračanin, \& Vingerhoets, 2019). Importantly, different neural networks have not only been found for negative and positive crying but also for admiration and compassion (Immordino-Yang, McColl, Damasio, \& Damasio, 2009), aesthetic beauty (Salimpoor, Benovoy, Larcher, Dagher, \& Zatorre, 2011; Wassiliwizky, Koelsch, Wagner, Jacobsen, \& Menninghaus, 2017), or elevation (Englander, Haidt, \& Morris, 2012). Future studies would need to disentangle the neural structures of positive tears and distinct categories. 
It should be noted that our model or taxonomy is in the first place descriptive. Primarily it aims at providing an overview of the space of positive emotional crying and how this space can be carved off. We do not assume universality of these mechanisms per se. While, according to our general approach, the occurrence of positive emotional crying is a universal phenomenon (Vingerhoets, 2013), we do not argue that the subjective feeling of, for example, beauty tears or the configuration of different aspects is ultimately the same. Instead, we would argue that these concepts may differ substantially across social, cultural, and historical contexts. Our data provide evidence that not all categories are experienced equally frequently or prevalent across different cultures. Our model would assume that achievement tears occur if there is a configuration or network between aspects such as perceptions or experiences of achievement, success or overcoming an obstacle, feelings of pride or admiration, being inspired, and experiences of positivity. While none of these aspects, except for positivity, is necessary or sufficient to allow the experience of achievement tears, the emotional network will likely differ within and between individuals with regard to its strength (see Fiske, Seibt, \& Schubert, 2017 for a similar account). Future studies need to test what kind of threshold in the configuration of the different aspects (i.e., the interplay among the building blocks of an emotion) needs to be achieved for the phenomenon to occur (see also Lange \& Zickfeld, 2019). Importantly, it will be of great interest to see how episodes of for example achievement with tears differ from similar situations without tears.

Importantly, we deviated from more conventional approaches in emotion psychology by not focusing on a specific type of emotion and then mapping its components, but instead focusing on one specific symptom, namely producing emotional tears in the context of positive emotions, and then exploring its various emotional nuances (see Maruskin, Thrash, \& Elliot, 2012 for a similar approach focusing on chills). In the end, we tend to conclude that the lexeme of feeling moved was most central in describing positive emotional crying. Here again, the three categories of achievement, beauty, and affection were qualitatively different from amusement. Being moved has been explored in the context of affection, achievement, and beauty in previous studies obtaining similar results (Landmann, Cova, \& Hess, 2019; Strick \& Van Soolingen, 2017). Thus, it seems that a wide variety of occurrences is associated with feeling moved. However, reviewing the literature has revealed that feeling moved is a somewhat fuzzy concept that can also be used in the context of negative valence (Zickfeld, Schubert, Seibt, \& Fiske, 2018). 
Thus, perhaps researchers should focus on more well-delineated concepts such as pride, admiration, elevation, awe, or kama muta when considering positive tears.

\section{Limitations}

The present project features several limitations with regard to theoretical and methodological aspects. First, as discussed earlier, it is rather descriptive and thus does not directly focus on a unifying mechanism of positive tears. Our main goal was to show that the phenomenon of positive tears exists in the first place as systematic empirical evidence has been sparse.

Second, as emphasized in our first step, qualitative approaches suffer invariably from a problem of subjectivity, which probably affects the structure of the model. Importantly, however, the main findings are strongly in line with theoretical predictions and are supported by previous theoretical literature.

Third, our methods were not always as effective at inducing or testing the intended effects, because we used several data sets of studies that were not specifically designed to address these topics. Moreover, as previously discussed, adherence to our manipulation was rather low in the UK sample in Study 3. At first, we speculated that this reflected a problem at remembering specific cases of beauty and amusement tears as they occur rather infrequently. However, surprisingly, amusement tears were reported to occur most frequently in Study $4 \mathrm{~b}$ and $4 \mathrm{c}$. As discussed earlier, this could also refer to the fact that amusement tears are qualitatively different from the other three categories. Future studies need to validate whether this is indeed the case and how amusement tears can be integrated into one coherent theoretical framework with the remaining categories except for the facts that they are positive and refer to emotional crying.

\section{Conclusion}

Shedding tears at winning a prestigious game, reading beautiful poetry, receiving an unexpected kindness, or hearing something surprisingly funny seems to be qualitatively different from crying due to being treated unfairly, being excluded, or losing a beloved person. The present studies provide strong systematic evidence for the existence of a class of positive tears that include a number of subcategories. We showed that each subcategory features different predictions and outcomes and is influenced by biological, cultural, social, and psychological factors. Research on emotional crying would need to account for these profound differences in order to validly represent the emotional space of positive tears. Positive tears might have important and distinct effects with regard to intrapersonal effects such as subjective well- 
being or emotion regulation and interpersonal effects such as the social signal in contrast to what previous studies on emotional crying have uncovered. The question of Should I laugh or should I cry? that the Swedish pop group ABBA posed in one of their songs seems to be answered with both in certain situations. 


\section{References}

Adamson, J. D. (1980). Tears of joy. The Canadian Journal of Psychiatry, 25(3), 264-265.

Algoe, S. B., \& Haidt, J. (2009). Witnessing excellence in action: The 'other-praising' emotions of elevation, gratitude, and admiration. The Journal of Positive Psychology, 4(2), 105-127. https://doi.org/10.1080/17439760802650519

Aragón, O. R., Clark, M. S., Dyer, R. L., \& Bargh, J. A. (2015). Dimorphous Expressions of Positive Emotion Displays of Both Care and Aggression in Response to Cute Stimuli. Psychological Science, 26(3), 259-273 https://doi.org/10.1177/0956797614561044

Bannister, S. (2018). A survey into the experience of musically induced chills: Emotions, situations and music. Psychology of Music. https://doi.org/10.1177/0305735618798024

Bates, D., Mächler, M., Bolker, B., \& Walker, S. (2014). Fitting linear mixed-effects models using lme4. Journal of Statistical Software.

Becht, M. C., \& Vingerhoets, A. J. (2002). Crying and mood change: A cross-cultural study. Cognition \& Emotion, 16(1), 87-101. https://doi.org/10.1080/02699930143000149

Bindra, D. (1972). Weeping, a problem of many facets. Bulletin of the British Psychological Society, 25, $281-284$.

Borgquist, A. (1906). Crying. The American Journal of Psychology, 17(2), 149-205.

Braud, W. (2001). Experiencing tears of wonder-joy: Seeing with the heart's eye. Journal of Transpersonal Psychology, 33(2), 99-112.

Braun, V., \& Clarke, V. (2006). Using thematic analysis in psychology. Qualitative Research in Psychology, 3(2), 77-101. https://doi.org/10.1191/1478088706qp063oa

Breiman, L. (2001). Random forests. Machine Learning, 45(1), 5-32.

Brennan, R. L. (2001). Some problems, pitfalls, and paradoxes in educational measurement. Educational Measurement: Issues and Practice, 20(4), 6-18.

Bylsma, L. M., Gračanin, A., \& Vingerhoets, A. J. (2019). The neurobiology of human crying. Clinical Autonomic Research, 29(1), 63-73.

Bylsma, L. M., Vingerhoets, A. J., \& Rottenberg, J. (2008). When is crying cathartic? An international study. Journal of Social and Clinical Psychology, 27(10), 1165-1187. 
Byrne, B. M., Shavelson, R. J., \& Muthén, B. (1989). Testing for the equivalence of factor covariance and mean structures: The issue of partial measurement invariance. Psychological Bulletin, 105(3), 456-466. https://doi.org/10.1037/0033-2909.105.3.456

Campbell, J. L., Quincy, C., Osserman, J., \& Pedersen, O. K. (2013). Coding in-depth semistructured interviews: Problems of unitization and intercoder reliability and agreement. Sociological Methods \& Research, 42(3), 294-320.

Colver, M. C., \& El-Alayli, A. (2015). Getting aesthetic chills from music: The connection between openness to experience and frisson. Psychology of Music, 44(3), 413-427. https://doi.org/10.1177/0305735615572358

Cordaro, D. T., Keltner, D., Tshering, S., Wangchuk, D., \& Flynn, L. M. (2016). The voice conveys emotion in ten globalized cultures and one remote village in Bhutan. Emotion, 16(1), 117-128.

Cova, F., \& Deonna, J. A. (2014). Being moved. Philosophical Studies, 169(3), 447-466. https://doi.org/10.1007/s11098-013-0192-9

Damen, F. (1999). Ontroering [Being touched] (Unpublished Master's thesis). University of Utrecht, Utrecht, the Netherlands.

Darwin, C. (1872). The expression of the emotions in man and animals. London, UK: John Murray.

De Fruyt, F. (1997). Gender and individual differences in adult crying. Personality and Individual Differences, 22(6), 937-940. https://doi.org/10.1016/S0191-8869(96)00264-4

de Melo C.M., Gratch J. (2009) Expression of Emotions Using Wrinkles, Blushing, Sweating and Tears. In: Ruttkay Z., Kipp M., Nijholt A., Vilhjálmsson H.H. (eds) Intelligent Virtual Agents. IVA 2009. Lecture Notes in Computer Science, vol 5773. Springer, Berlin, Heidelberg

Denckla, C. A., Fiori, K. L., \& Vingerhoets, A. J. J. M. (2014). Development of the Crying Proneness Scale: Associations Among Crying Proneness, Empathy, Attachment, and Age. Journal of Personality Assessment, 96(6), 619-631. https://doi.org/10.1080/00223891.2014.899498

Descartes, R. (1989). Passions of the Soul. Hackett Publishing.

Dolan, P., Peasgood, T., \& White, M. (2008). Do we really know what makes us happy? A review of the economic literature on the factors associated with subjective well-being. Journal of Economic Psychology, 29(1), 94-122. https://doi.org/10.1016/j.joep.2007.09.001

Efran, J. S., \& Spangler, T. J. (1979). Why grown-ups cry. Motivation and Emotion, 3(1), 63-72. 
Englander, Z. A., Haidt, J., \& Morris, J. P. (2012). Neural Basis of Moral Elevation Demonstrated through Inter-Subject Synchronization of Cortical Activity during Free-Viewing. PLOS ONE, 7(6), e39384. https://doi.org/10.1371/journal.pone.0039384

Engvik, H., \& Clausen, S.-E. (2011). Norsk kortversjon av big five inventory (BFI-20). Tidsskrift for Norsk Psykologforening, 48(9), 869-872.

Feldman, S. S. (1956). Crying at the happy ending. Journal of the American Psychoanalytic Association, 4(3), 477-485.

Fiske, A. P., Seibt, B., \& Schubert, T. W. (2017). The sudden devotion emotion: Kama muta and the cultural practices whose function is to evoke it. Emotion Review, 11(1), 74-86. https://doi.org/10.1177/1754073917723167.

Fredrickson, B. L., \& Branigan, C. (2005). Positive emotions broaden the scope of attention and thoughtaction repertoires. Cognition and Emotion, 19(3), 313-332.

https://doi.org/10.1080/02699930441000238

Frey, W. H. (1985). Crying, the mystery of tears. Minneapolis, MN: Winston Press.

Frey, W. H., Hoffman-Ahern, C., Johnson, R. A., Lykken, D. T., \& Tuason, V. B. (1983). Crying behavior in the human adult. Integrative Psychiatry, 1, 94-100.

Frijda, N. H. (1986). The emotions: Studies in emotion and social interaction. Paris: Maison de Sciences de l'Homme. Retrieved from http://library.perbanas.ac.id/images/book/PHKI1 1/the\%20emotions.pdf

Goetz, J. L., Keltner, D., \& Simon-Thomas, E. (2010). Compassion: An evolutionary analysis and empirical review. Psychological Bulletin, 136(3), 351.

Gračanin, A., Bylsma, L. M., \& Vingerhoets, A. J. J. M. (2017). The Communicative and Social Functions of Human Crying. In J.-M. Fernández-Dols \& J. A. Russell (Eds.), The Science of Facial Expression (pp. 217-233). New York, NY, US: Oxford University Press.

Gračanin, A., Bylsma, L. M., \& Vingerhoets, A. J. J. M. (2018). Why Only Humans Shed Emotional Tears. Human Nature, 29(2), 1-30. https://doi.org/10.1007/s12110-018-9312-8

Graham, L. E., Thomson, A. L., Nakamura, J., Brandt, I. A., \& Siegel, J. T. (2017). Finding a family: A categorization of enjoyable emotions. The Journal of Positive Psychology, 14(2), 206-229. https://doi.org/10.1080/17439760.2017.1402074 
Haidt, J. (2003). Elevation and the positive psychology of morality. In C. L. M. Keyes \& J. Haidt (Eds.), Flourishing: Positive psychology and the life well-lived (pp. 278-289). Retrieved from http://drdavidlawrence.com/wp-content/uploads/2015/12/Flourishing-Positive-psychology-andthe-life-well-lived.pdf\#page $=252$

Hoffman, E., Garg, N. R., \& González-Mujica, J. (2013). Tears of joy in India. Indian Journal of Positive Psychology, 4(2), 212.

IJzerman, H., Lindenberg, S., Dalğar, İ., Weissgerber, S. S. C., Vergara, R. C., Cairo, A. H., ... Zickfeld, J. H. (2018). The Human Penguin Project: Climate, Social Integration, and Core Body Temperature. Collabra: Psychology, 4(1), 37. https://doi.org/10.1525/collabra.165

Immordino-Yang, M. H., McColl, A., Damasio, H., \& Damasio, A. (2009). Neural correlates of admiration and compassion. Proceedings of the National Academy of Sciences, 106(19), 8021-8026.

James, W. (1890). The principles of psychology. Cambridge, MA: Harvard University Press.

Jolliffe, D., \& Farrington, D. P. (2006). Development and validation of the Basic Empathy Scale. Journal of Adolescence, 29(4), 589-611.

Keltner, D., \& Bonanno, G. A. (1997). A study of laughter and dissociation: Distinct correlates of laughter and smiling during bereavement. Journal of Personality and Social Psychology, 73(4), 687.

Keltner, D., \& Haidt, J. (2003). Approaching awe, a moral, spiritual, and aesthetic emotion. Cognition and Emotion, 17(2), 297-314.

Kottler, J. A. (1996). The language of tears. San Francisco, CA: Jossey-Bass.

Kraemer, D. L., \& Hastrup, J. L. (1986). Crying in natural settings: Global estimates, self-monitored frequencies, depression and sex differences in an undergraduate population. Behaviour Research and Therapy, 24(3), 371-373. https://doi.org/10.1016/0005-7967(86)90199-3

Krys, K., -Melanie Vauclair, C., Capaldi, C. A., Lun, V. M.-C., Bond, M. H., Domínguez-Espinosa, A., ... Yu, A. A. (2016). Be Careful Where You Smile: Culture Shapes Judgments of Intelligence and Honesty of Smiling Individuals. Journal of Nonverbal Behavior, 40(2), 101-116. https://doi.org/10.1007/s10919-015-0226-4

Lakens, D., Adolfi, F. G., Albers, C. J., Anvari, F., Apps, M. A., Argamon, S. E., ... Bradford, D. E. (2018). Justify your alpha. Nature Human Behaviour, 2(3), 168-171. https://doi.org/10.1038/s41562-018-0311-x 
Landmann, H., Cova, F., \& Hess, U. (2019). Being moved by meaningfulness: Appraisals of surpassing internal standards elicit being moved by relationships and achievements. Cognition and Emotion, $1-23$.

Lange, J., \& Zickfeld, J. H. (2019). Estimating overlapping causal emotions networks. Manuscript in preparation.

Löfgren, L. B. (1966). On weeping. International Journal of Psychoanalysis, 47, 375-381.

Lund, F. H. (1930). Why do we weep? Journal of Social Psychology, 1, 136-151.

MacArthur, H. J., \& Shields, S. A. (2015). There's No Crying in Baseball, or Is There? Male Athletes, Tears, and Masculinity in North America. Emotion Review, 7(1), 39-46. https://doi.org/10.1177/1754073914544476

Martin, R. A. (2007). The psychology of humor. An integrative approach. Burlington, MA: Elsevier Academic Press.

Maruskin, L. A., Thrash, T. M., \& Elliot, A. J. (2012). The chills as a psychological construct: Content universe, factor structure, affective composition, elicitors, trait antecedents, and consequences. Journal of Personality and Social Psychology, 103(1), 135-157. https://doi.org/10.1037/a0028117

McCrae, R. R. (2007). Aesthetic Chills as a Universal Marker of Openness to Experience. Motivation and Emotion, 31(1), 5-11. https://doi.org/10.1007/s11031-007-9053-1

Mendiburo-Seguel, A., Páez, D., \& Martínez-Sánchez, F. (2015). Humor styles and personality: A metaanalysis of the relation between humor styles and the Big Five personality traits. Scandinavian Journal of Psychology, 56(3), 335-340. https://doi.org/10.1111/sjop.12209

Menninghaus, W., Wagner, V., Hanich, J., Wassiliwizky, E., Kuehnast, M., \& Jacobsen, T. (2015). Towards a psychological construct of being moved. PloS One, 10(6), e0128451.

Miceli, M., \& Castelfranchi, C. (2003). Crying: Discussing its basic reasons and uses. New Ideas in Psychology, 21(3), 247-273. https://doi.org/10.1016/j.newideapsych.2003.09.001

Millings, A., Hepper, E. G., Hart, C. M., Swift, L., \& Rowe, A. C. (2016). Holding Back the Tears: Individual Differences in Adult Crying Proneness Reflect Attachment Orientation and Attitudes to Crying. Frontiers in Psychology, 7. https://doi.org/10.3389/fpsyg.2016.01003

Murube, J., Murube, L., \& Murube, A. (1999). Origin and types of emotional tearing. European Journal of Ophthalmology, 9(2), 77-84. 
Nelson, J. K. (2005). Seeing through tears: Crying and attachment. New York, NY: Routledge.

Niedenthal, P. M., Rychlowska, M., Wood, A., \& Zhao, F. (2018). Heterogeneity of long-history migration predicts smiling, laughter and positive emotion across the globe and within the United States. PLoS ONE, 13(8), 1-17. https://doi.org/10.1371/journal.pone.0197651

Onu, D., Kessler, T., \& Smith, J. R. (2016). Admiration: A Conceptual Review. Emotion Review, 8(3), 218-230.. https://doi.org/10.1177/1754073915610438

Paulhus, D. L., \& Vazire, S. (2007). The self-report method. In R. W. Robins \& R. C. Fraley (Eds.), Handbook of research methods in personality psychology (pp. 224-239). New York, NY: Guilford Press.

Pelowski, M. (2015). Tears and transformation: Feeling like crying as an indicator of insightful or "aesthetic" experience with art. Frontiers in Psychology, 6. https://doi.org/10.3389/fpsyg.2015.01006

Peng, K., \& Nisbett, R. E. (1997). Validity problems comparing values across cultures and possible solutions. Psychological Methods, 2(4), 329-344. https://doi.org/10.1037/1082-989X.2.4.329

Peter, M., Vingerhoets, A. J. J. M., \& Heck, G. L. V. (2001). Personality, gender, and crying. European Journal of Personality, 15(1), 19-28. https://doi.org/10.1002/per.386

Rosenblatt, P. C., Walsh, R. P., \& Jackson, D. A. (1976). Grief and Mourning in Cross-Cultural Perspective. New Haven, CT: Human Relations Area Files, Inc.

Rottenberg, J., Bylsma, L. M., Wolvin, V., \& Vingerhoets, A. J. J. M. (2008). Tears of sorrow, tears of joy: An individual differences approach to crying in Dutch females. Personality and Individual Differences, 45(5), 367-372. https://doi.org/10.1016/j.paid.2008.05.006

Rottenberg, J., \& Vingerhoets, A. J. (2012). Crying: Call for a lifespan approach. Social and Personality Psychology Compass, 6(3), 217-227.

Russell, L. (2018). Emmeans: Estimated marginal means, aka least-squares means. R Package Version, $1(2)$.

Sadoff, R. L. (1966). On the nature of crying and weeping. Psychiatric Quarterly, 40(1), 490-503.

Salimpoor, V. N., Benovoy, M., Larcher, K., Dagher, A., \& Zatorre, R. J. (2011). Anatomically distinct dopamine release during anticipation and experience of peak emotion to music. Nature Neuroscience, 14(2), 257-262. https://doi.org/10.1038/nn.2726 
Sauter, D. A. (2017). The nonverbal communication of positive emotions: An emotion family approach. Emotion Review, 9(3), 222-234.

Sauter, D. A., Eisner, F., Ekman, P., \& Scott, S. K. (2010). Cross-cultural recognition of basic emotions through nonverbal emotional vocalizations. Proceedings of the National Academy of Sciences, 107(6), 2408-2412.

Scheirs, J. G. M., \& Sijtsma, K. (2001). The study of crying: Some methodological considerations and a comparison of methods for analyzing questionnaires. In A. J. J. M. Vingerhoets \& R. R. Cornelius (Eds.), Adult crying. A biopsychosocial approach (pp. 277-298). Hove, UK: Brunner-Routledge.

Scherer, K. R., \& Zentner, M. R. (2001). Emotional effects of music: Production rules. Music and Emotion: Theory and Research, 361-392.

Schieman, S., \& Van Gundy, K. (2000). The personal and social links between age and self-reported empathy. Social Psychology Quarterly,63(2), 152-174.

Schönbrodt, F. D., \& Perugini, M. (2013). At what sample size do correlations stabilize? Journal of Research in Personality, 47(5), 609-612. https://doi.org/10.1016/j.jrp.2013.05.009

Schubert, T. W., Zickfeld, J. H., Seibt, B., \& Fiske, A. P. (2016). Moment-to-Moment Changes in Being Moved Match Changes in Perceived Closeness, Weeping, Goosebumps, and Warmth: Time Series Analyses. Cognition and Emotion, 32(1), 174-185.

https://doi.org/10.1080/02699931.2016.1268998

Seibt, B., Schubert, T. W., Zickfeld, J. H., \& Fiske, A. P. (2017). Interpersonal closeness and morality predict feelings of being moved. Emotion, 17(3), 389-394. https://doi.org/10.1037/emo0000271

Silvia, P. J., Fayn, K., Nusbaum, E. C., \& Beaty, R. E. (2015). Openness to experience and awe in response to nature and music: Personality and profound aesthetic experiences. Psychology of Aesthetics, Creativity, and the Arts, 9(4), 376.

Solt, F., Habel, P., \& Grant, J. T. (2011). Economic Inequality, Relative Power, and Religiosity*. Social Science Quarterly, 92(2), 447-465. https://doi.org/10.1111/j.1540-6237.2011.00777.x

Srivastava, P., \& Hopwood, N. (2009). A practical iterative framework for qualitative data analysis. International Journal of Qualitative Methods, 8(1), 76-84. 
Steinnes, K. K., Blomster, J. K., Seibt, B., Zickfeld, J. H., \& Fiske, A. P. (2019). Too Cute for Words: Cuteness Evokes the Heartwarming Emotion of Kama Muta. Frontiers in Psychology, 10. https://doi.org/10.3389/fpsyg.2019.00387

Stellar, J. E., Gordon, A. M., Piff, P. K., Cordaro, D., Anderson, C. L., Bai, Y., ... Keltner, D. (2017). SelfTranscendent Emotions and Their Social Functions: Compassion, Gratitude, and Awe Bind Us to Others Through Prosociality. Emotion Review, 9(3), 200-207. https://doi.org/10.1177/1754073916684557

Strick, M., \& Van Soolingen, J. (2017). Against the odds: Human values arising in unfavourable circumstances elicit the feeling of being moved. Cognition and Emotion, 32(6), 1231-1246. https://doi.org/10.1080/02699931.2017.1395729

Tan, E. S., \& Frijda, N. H. (1999). Sentiment in film viewing. In C. Plantinga \& G. M. Smith (Eds.), Passionate views. Film, cognition and emotion (pp. 48-64). Baltimore, MD: John Hopkins University Press.

Tashakkori, A., \& Teddlie, C. (1998). Mixed Methodology: Combining Qualitative and Quantitative Approaches. Thousand Oaks, CA: Sage.

Thomson, A. L., \& Siegel, J. T. (2016). Elevation: A review of scholarship on a moral and other-praising emotion. The Journal of Positive Psychology, 12(6), 628-638. https://doi.org/10.1080/17439760.2016.1269184

Tracy, J. L., \& Robins, R. W. (2004). Show Your Pride: Evidence for a Discrete Emotion Expression. Psychological Science, 15(3), 194-197. https://doi.org/10.1111/j.0956-7976.2004.01503008.x

Tracy, J. L., \& Robins, R. W. (2007). The psychological structure of pride: A tale of two facets. Journal of Personality and Social Psychology, 92(3), 506-525. https://doi.org/10.1037/0022-3514.92.3.506

Tracy, J. L., Shariff, A. F., \& Cheng, J. T. (2010). A Naturalist's View of Pride. Emotion Review, 2(2), 163-177. https://doi.org/10.1177/1754073909354627

van Hemert, D. A., van de Vijver, F. J. R., \& Vingerhoets, A. J. J. M. (2011). Culture and Crying: Prevalences and Gender Differences. Cross-Cultural Research, 45(4), 399-431. https://doi.org/10.1177/1069397111404519

Vingerhoets, A. J. J. M. (2013). Why Only Humans Weep: Unravelling the mysteries of tears. Oxford, UK: Oxford University Press. 
Vingerhoets, A. J. J. M., \& Becht, M. C. (1997). The ISAC study: Some preliminary findings. Poster Presented at the Annual Meeting of the American Psychosomatic Society, Santa Fe, NM.

Vingerhoets, A. J. J. M., Boelhouwer, A. J. W., Van Tilburg, M. A. L., \& Van Heck, G. L. (2001). The situational and emotional context of adult crying. In A. J. J. M. Vingerhoets \& R. R. Cornelius (Eds.), Adult crying. A biopsychosocial approach. (pp. 71-90). Hove, UK: Brunner-Routledge.

Vingerhoets, A. J. J. M., \& Bylsma, L. M. (2015). The Riddle of Human Emotional Crying: A Challenge for Emotion Researchers. Emotion Review,8(3), 207-217. https://doi.org/10.1177/1754073915586226

Vingerhoets, A. J. J. M., \& Cornelius, R. R. (2001). Adult Crying: A Biopsychosocial Approach. Hove, UK: Brunner-Routledge.

Vingerhoets, A. J. J. M., Rottenberg, J., Cevaal, A., \& Nelson, J. K. (2007). Is there a relationship between depression and crying? A review. Acta Psychiatrica Scandinavica, 115(5), 340-351. https://doi.org/10.1111/j.1600-0447.2006.00948.x

Vingerhoets, A. J. J. M., van Geleuken, A. J. M. L., van Tilburg, M. A. L., \& van Heck, G. L. (1997). The psychological context of crying episodes: Towards a model of adult crying. In A. J. J. M. Vingerhoets, F. van Bussel, \& A. Boelhouwer (Eds.), The (non)expression of emotions in health and disease.. (pp. 323-336). Tilburg: Tilburg University Press.

Wassiliwizky, E., Jacobsen, T., Heinrich, J., Schneiderbauer, M., \& Menninghaus, W. (2017). Tears Falling on Goosebumps: Co-occurrence of Emotional Lacrimation and Emotional Piloerection Indicates a Psychophysiological Climax in Emotional Arousal. Frontiers in Psychology, 8. https://doi.org/10.3389/fpsyg.2017.00041

Wassiliwizky, E., Koelsch, S., Wagner, V., Jacobsen, T., \& Menninghaus, W. (2017). The emotional power of poetry: Neural circuitry, psychophysiology, compositional principles. Social Cognitive and Affective Neuroscience, 12(8), 1229-1240. https://doi.org/10.1093/scan/nsx069

Weiss, J. (1952). Crying at the happy ending. The Psychoanalytic Review (1913-1957), 39, 338.

Williams, D. G., \& Morris, G. H. (1996). Crying, weeping or tearfulness in British and Israeli adults. British Journal of Psychology, 87(3), 479-505.

Wood, E. C., \& Wood, C. D. (1984). Tearfulness: A psychoanalytic interpretation. Journal of the American Psychoanalytic Association, 32(1), 117-136. 
Young, P. T. (1937). Laughing and weeping, cheerfulness and depression: A study of moods among college students. Journal of Social Psychology, 8, 311-334.

Zickfeld, J. H. (2018). The nature of music-induced sadness and the role of kama muta: Comment on "An integrative review of the enjoyment of sadness associated with music" by Eerola et al. Physics of Life Reviews, 25, 139-141. https://doi.org/10.1016/j.plrev.2018.03.005

Zickfeld, J. H., Schubert, T. W., Seibt, B., Blomster, J. K., Arriaga, P., Basabe, N., ... Fiske, A. P. (2018). Kama Muta: Conceptualizing and Measuring the Experience of Being Moved Across 19 Nations and 15 Languages. Emotion, 19(3), 402-424. https://doi.org/10.1037/emo0000450

Zickfeld, J. H., Schubert, T. W., Seibt, B., \& Fiske, A. P. (2017). Empathic Concern Is Part of a More General Communal Emotion. Frontiers in Psychology, 8. https://doi.org/10.3389/fpsyg.2017.00723

Zickfeld, J. H., Schubert, T. W., Seibt, B., \& Fiske, A. P. (2018). Moving Through the Literature: What is the Emotion Often Denoted Being Moved? Emotion Review, 11(2), 123-139. https://doi.org/10.1177/1754073918820126

Zickfeld, J. H., van de Ven, N., Schubert, T. W., \& Vingerhoets, A. (2018). Are tearful individuals perceived as less competent? Probably not. Comprehensive Results in Social Psychology, 1-21. https://doi.org/10.1080/23743603.2018.1514254 


\section{Table 1}

Overview of categories emerging from Study 1 and frequencies for the US and Norwegian sample.

\begin{tabular}{|c|c|c|c|}
\hline \multirow[t]{2}{*}{ Main Category } & \multirow[t]{2}{*}{ Subcategory } & \multicolumn{2}{|c|}{$n($ Frequency $\%)$} \\
\hline & & US & Norway \\
\hline \multicolumn{4}{|l|}{$\begin{array}{l}\text { Achieving/making } \\
\text { progress towards a } \\
\text { valued goal }\end{array}$} \\
\hline & Sports/exercise & $7(3.87)$ & $5(3.52)$ \\
\hline & Hobby & $3(1.66)$ & $1(.70)$ \\
\hline & Work & $3(1.66)$ & $3(2.11)$ \\
\hline & School & $5(2.76)$ & $8(5.63)$ \\
\hline & Other & $3(1.66)$ & $5(3.52)$ \\
\hline & Total & $21(11.6)$ & $22(15.49)$ \\
\hline $\begin{array}{l}\text { Recovery after } \\
\text { adversity/illness }\end{array}$ & & $14(7.73)$ & $1(.70)$ \\
\hline \multirow{7}{*}{$\begin{array}{l}\text { Positive event after a } \\
\text { time of adversity } \\
\text { Life transition of self } \\
\text { or close others }\end{array}$} & & $11(6.08)$ & $4(2.82)$ \\
\hline & Graduation & $8(4.42)$ & - \\
\hline & Wedding/Engagement & $6(3.31)$ & $7(4.93)$ \\
\hline & Birth/Pregnancy & $7(3.87)$ & $6(4.23)$ \\
\hline & Milestone of child & $4(2.21)$ & - \\
\hline & Leaving a job & $1(.55)$ & - \\
\hline & Total & $26(14.36)$ & $13(9.15)$ \\
\hline \multicolumn{4}{|l|}{ Relationship changes } \\
\hline & Reunion & $6(3.31)$ & $9(6.34)$ \\
\hline & $\begin{array}{l}\text { Progression in } \\
\text { relationship }\end{array}$ & $7(3.87)$ & $8(5.63)$ \\
\hline & Other & $2(1.10)$ & - \\
\hline & Total & $15(8.29)$ & 17 (11.97) \\
\hline \multicolumn{4}{|l|}{$\begin{array}{l}\text { Expressions of } \\
\text { love/care/appreciation }\end{array}$} \\
\hline & From child & $8(4.42)$ & $1(.70)$ \\
\hline & $\begin{array}{l}\text { From romantic } \\
\text { partner }\end{array}$ & $3(1.66)$ & $8(5.63)$ \\
\hline & From family & $1(.55)$ & $7(4.93)$ \\
\hline & $\begin{array}{l}\text { From } \\
\text { friend/acquaintance }\end{array}$ & $2(1.10)$ & $10(7.04)$ \\
\hline & Other & $8(4.42)$ & $2(1.41)$ \\
\hline & Total & $22(12.15)$ & $28(19.72)$ \\
\hline \multicolumn{4}{|l|}{ Unexpected kindness } \\
\hline & From stranger & $5(2.76)$ & $2(1.41)$ \\
\hline & $\begin{array}{l}\text { From } \\
\text { friends/acquaintance }\end{array}$ & $2(1.10)$ & $6(4.23)$ \\
\hline & From child & $5(2.76)$ & $1(.70)$ \\
\hline & $\begin{array}{l}\text { From romantic } \\
\text { partner }\end{array}$ & - & $2(1.41)$ \\
\hline & Total & $12(6.63)$ & $11(7.75)$ \\
\hline \multicolumn{4}{|l|}{$\begin{array}{l}\text { Receiving financial } \\
\text { help }\end{array}$} \\
\hline & From friend & $3(1.66)$ & - \\
\hline & From family & $4(2.21)$ & - \\
\hline & Total & $7(3.87)$ & - \\
\hline
\end{tabular}




\begin{tabular}{|c|c|c|c|}
\hline $\begin{array}{l}\text { Sharing an emotional } \\
\text { moment with } \\
\text { someone }\end{array}$ & & $5(2.76)$ & $9(6.34)$ \\
\hline $\begin{array}{l}\text { Appreciating } \\
\text { something beautiful }\end{array}$ & & & \\
\hline & Music & $1(.55)$ & $3(2.11)$ \\
\hline & Nature & $1(.55)$ & $2(1.41)$ \\
\hline & Other & - & $3(2.11)$ \\
\hline & Total & $2(1.10)$ & $8(5.63)$ \\
\hline $\begin{array}{l}\text { Remembering dead } \\
\text { loved ones }\end{array}$ & & $4(2.21)$ & $1(.70)$ \\
\hline & Birthdays & $5(2.76)$ & $2(1.41)$ \\
\hline $\begin{array}{l}\text { Parent-child } \\
\text { relationships }\end{array}$ & & $24(13.26)$ & - \\
\hline Religious experience & & & \\
\hline & Love of God or Jesus & $1(.55)$ & $1(.70)$ \\
\hline & Community & $3(1.66)$ & $2(1.41)$ \\
\hline & Total & $4(2.21)$ & $3(2.11)$ \\
\hline $\begin{array}{l}\text { Life is good, } \\
\text { harmony }\end{array}$ & & - & $5(3.52)$ \\
\hline Nostalgia & & - & $5(3.52)$ \\
\hline Amusement & & $2(1.10)$ & $6(4.23)$ \\
\hline Happiness & & - & $2(1.41)$ \\
\hline Sadness & & $2(1.10)$ & $3(2.11)$ \\
\hline Other & & - & $1(.70)$ \\
\hline No coherent story & & $1(.55)$ & - \\
\hline Total & & 181 & 142 \\
\hline
\end{tabular}

Note. The final number of codes do not correspond to the total number of episodes as it was possible that an episode was coded belonging to several main categories. 
Table 2

Overview of coding categories in Study 2 and frequencies across the different countries

\begin{tabular}{|c|c|c|c|c|c|c|c|}
\hline & \multicolumn{6}{|c|}{ Frequency $(\%)$} & \multirow[b]{2}{*}{ Total } \\
\hline & Achievement & Beauty & Affection & Amusement & Not Positive & Excluded & \\
\hline China & $36(27.5)$ & $11(8.4)$ & $75(57.3)$ & - & $7(5.3)$ & $2(1.5)$ & 131 \\
\hline Serbia & $62(25.5)$ & $20(8.2)$ & $142(58.4)$ & $7(2.9)$ & $8(3.3)$ & $4(1.6)$ & 243 \\
\hline Netherlands & $100(36.9)$ & $22(8.1)$ & $132(48.7)$ & $10(3.7)$ & $6(2.2)$ & $1(.4)$ & 271 \\
\hline Australia & $22(22.4)$ & $7(7.1)$ & $60(61.2)$ & $4(4.1)$ & $4(4.1)$ & $1(1.0)$ & 98 \\
\hline South Africa & $17(37.8)$ & $3(6.7)$ & $21(46.7)$ & - & $4(8.9)$ & - & 45 \\
\hline Finland & $33(23.2)$ & $20(14.1)$ & $84(59.2)$ & $3(2.1)$ & $2(1.4)$ & - & 142 \\
\hline Spain & $48(30.8)$ & $6(3.8)$ & $82(52.6)$ & $8(5.1)$ & $9(5.8)$ & $3(1.9)$ & 156 \\
\hline Total & $318(29.3)$ & $89(8.2)$ & $596(54.9)$ & $32(2.9)$ & $40(3.7)$ & $11(1.01)$ & 1086 \\
\hline
\end{tabular}

Note: Percentages indicate fractions within each country. 
Table 3

Estimated means and 95\% CIs across all countries in Study 2 for the different coding categories

\begin{tabular}{|c|c|c|c|c|c|}
\hline & \multicolumn{5}{|c|}{ Type of Tears } \\
\hline Item & Negative & Achievement & Beauty & Affection & Amusement \\
\hline I had positive feelings & $1.54[1.11,1.97]$ & $5.52[5.08,5.96]$ & $5.50[5.01,5.99]$ & $5.53[5.10,5.96]$ & $5.76[5.12,6.39]$ \\
\hline I had negative feelings & $5.07[4.76,5.38]$ & $1.22[.89,1.54]$ & $1.52[1.12,1.93]$ & $1.40[1.09,1.72]$ & $0.63[0.05,1.21]$ \\
\hline Goosebumps or hair standing up & $1.92[1.16,2.69]$ & $2.43[1.66,3.20]$ & $3.17[2.36,3.98]$ & $2.15[1.39,2.92]$ & $0.49[-0.44,1.43]$ \\
\hline Chills or shivers & $2.47[1.91,3.03]$ & $2.00[1.43,2.57]$ & $2.62[1.99,3.26]$ & $1.56[1.00,2.13]$ & $0.80[-0.02,1.62]$ \\
\hline A warm feeling in the center of the chest & $1.37[1.02,1.73]$ & $3.87[3.49,4.24]$ & $4.11[3.63,4.59]$ & $4.29[3.93,4.65]$ & $2.91[2.22,3.59]$ \\
\hline Some feeling in the center of the chest & $3.94[3.71,4.17]$ & $3.55[3.27,3.82]$ & $4.04[3.62,4.46]$ & $3.79[3.55,4.03]$ & $2.45[1.79,3.10]$ \\
\hline Choked up & $3.43[2.54,4.33]$ & $2.17[1.27,3.06]$ & $2.08[1.16,3.01]$ & $2.20[1.21,3.10]$ & $1.51[0.48,2.54]$ \\
\hline A lump in the throat & $4.50[3.96,5.03]$ & $2.69[2.15,3.23]$ & $2.93[2.32,3.54]$ & $2.82[2.29,3.36]$ & $0.59[-0.20,1.38]$ \\
\hline Difficulty speaking & $3.60[3.16,4.05]$ & $2.19[1.73,2.65]$ & $2.19[1.64,2.75]$ & $2.30[1.85,2.75]$ & $3.03[2.26,3.80]$ \\
\hline I put one or both hands to my chest & $1.87[1.51,2.23]$ & $1.95[1.56,2.33]$ & $1.81[1.32,2.30]$ & $1.88[1.52,2.25]$ & $1.61[0.91,2.32]$ \\
\hline I took a deep breath or held my breath & $3.93[3.55,4.31]$ & $3.17[2.77,3.57]$ & $3.44[2.93,3.95]$ & $2.76[2.38,3.15]$ & $2.29[1.56,3.03]$ \\
\hline I said something like 'Awww' & $1.30[0.63,1.96]$ & $2.58[1.91,3.25]$ & $2.50[1.77,3.22]$ & $2.64[1.97,3.30]$ & $1.75[0.86,2.64]$ \\
\hline I smiled & $1.00[0.64,1.35]$ & $5.19[4.82,5.56]$ & $5.10[4.65,5.55]$ & $5.00[4.64,5.36]$ & $5.47[4.84,6.10]$ \\
\hline I giggled & $0.73[0.62,0.83]$ & $2.82[2.62,3.02]$ & $2.05[1.68,2.42]$ & $2.53[2.39,2.68]$ & $3.95[3.33,4.57]$ \\
\hline I frowned & $3.38[2.93,3.83]$ & $1.09[0.64,1.56]$ & $0.83[0.29,1.36]$ & $1.08[0.63,1.53]$ & $1.30[0.58,2.02]$ \\
\hline I lowered my head & $3.83[3.40,4.26]$ & $1.61[1.16,2.05]$ & $1.51[0.97,2.05]$ & $1.68[1.25,2.11]$ & $1.84[1.08,2.59]$ \\
\hline Refreshed, energized, or exhilarated & $1.32[1.04,1.60]$ & $4.00[3.69,4.32]$ & $4.19[3.75,4.64]$ & $3.76[3.47,4.05]$ & $3.47[2.79,4.15]$ \\
\hline Buoyant or light & $0.89[0.52,1.26]$ & $4.91[4.53,5.29]$ & $4.61[4.16,5.07]$ & $4.36[3.99,4.74]$ & $4.88[4.26,5.50]$ \\
\hline Communal Sharing & $2.02[1.36,2.69]$ & $3.18[2.51,3.85]$ & $3.93[3.23,4.63]$ & $4.64[3.97,5.30]$ & $3.26[2.44,4.07]$ \\
\hline I felt/observed a connection that was broken & $2.86[2.26,3.47]$ & $0.94[0.32,1.55]$ & $1.17[0.50,1.85]$ & $1.00[0.39,1.61]$ & $0.57[-0.27,1.40]$ \\
\hline I felt/observed something comical & $1.07[0.00,2.15]$ & $1.63[0.55,2.71]$ & $1.53[0.45,2.62]$ & $1.97[0.89,3.04]$ & $5.75[4.61,6.88]$ \\
\hline Communal Sharing Motivation & $3.05[2.59,3.51]$ & $3.47[3.00,3.94]$ & $3.24[2.71,3.76]$ & $4.47[4.01,4.93]$ & $2.27[1.60,2.94]$ \\
\hline I wanted to be consoled & $4.18[3.54,4.82]$ & $1.49[0.85,2.14]$ & $1.26[.56,1.96]$ & $1.73[1.09,2.37]$ & $0.63[-0.23,1.50]$ \\
\hline I felt like joking & $1.02[0.29,1.75]$ & $2.56[1.82,3.29]$ & $1.73[.97,2.50]$ & $2.33[1.60,3.07]$ & $4.93[4.05,5.80]$ \\
\hline It was heartwarming & $1.30[0.82,1.77]$ & $4.25[3.76,4.73]$ & $4.73[4.18,5.28]$ & $5.10[4.62,5.58]$ & $2.68[1.97,3.38]$ \\
\hline I was moved & $2.95[2.41,3.49]$ & $3.99[3.44,4.54]$ & $4.88[4.25,5.52]$ & $4.86[4.32,5.41]$ & $1.20[0.37,2.04]$ \\
\hline I was touched & $3.14[2.13,4.14]$ & $4.01[3.00,5.02]$ & $4.85[3.82,5.88]$ & $4.79[3.79,5.80]$ & $1.88[0.75,3.01]$ \\
\hline It was a nostalgic moment & $1.96[1.29,2.62]$ & $2.90[2.23,3.58]$ & $3.65[2.91,4.39]$ & $3.21[2.55,3.88]$ & $1.84[0.90,2.79]$ \\
\hline It was a poignant experience & $3.58[2.74,4.41]$ & $2.90[2.06,3.74]$ & $2.40[1.51,3.28]$ & $2.68[1.85,3.51]$ & $0.85[-0.19,1.88]$ \\
\hline
\end{tabular}


I felt a part of something largen than myself I fell in love

I felt sad

$\begin{array}{llllll} & 3.40 & {[2.86,3.94]} & 4.53[3.92,5.15] & 3.55[3.02,4.08] & 2.09[1.26,2.91]\end{array}$

$1.29[0.22,2.37] \quad 2.05[0.97,3.13] \quad 2.63[1.53,3.72] \quad 3.06[1.98,4.13] \quad 1.55[0.38,2.71]$

I was awed

$\begin{array}{llllll}5.22[4.92,5.53] & 1.23[0.91,1.55] & 1.58[1.17,1.99] & 1.56[1.25,1.87] & 0.40[-0.18,0.99]\end{array}$

I was amused

$\begin{array}{llllll}2.00[1.02,2.97] & 3.19[2.21,4.16] & 4.16[3.16,5.16] & 3.19[2.21,4.17] & 1.24[0.14,2.34]\end{array}$

$0.71[0.01,1.41] \quad 2.82[2.11,3.52] \quad 2.87[2.14,3.61] \quad 2.78[2.08,3.48] \quad 5.74[4.89,6.59]$ 
Table 4

Estimated means and 95\% CIs across all countries in Study 3 for the different coded categories

\begin{tabular}{|c|c|c|c|c|c|}
\hline Item & $\begin{array}{c}\text { Total } \\
(\mathrm{n}=431)\end{array}$ & $\begin{array}{l}\text { Achievement } \\
\quad(\mathrm{n}=143)\end{array}$ & $\begin{array}{l}\text { Beauty } \\
(\mathrm{n}=38)\end{array}$ & $\begin{array}{l}\text { Affection } \\
(\mathrm{n}=178)\end{array}$ & $\begin{array}{l}\text { Amusement } \\
(\mathrm{n}=72)\end{array}$ \\
\hline I had positive feelings & $5.60(.82)$ & $5.54[5.41,5.68]$ & $5.74[5.48,6.00]$ & $5.61[5.49,5.73]$ & $5.60[5.41,5.79]$ \\
\hline I had negative feelings & $.91(1.48)$ & $0.92[0.68,1.17]$ & $0.61[0.14,1.07]$ & $1.07[0.86,1.29]$ & $0.65[0.30,0.99]$ \\
\hline Tears & $4.19(1.52)$ & $4.29[4.04,4.54]$ & $3.71[3.23,4.20]$ & $4.26[4.04,4.49]$ & $4.04[3.69,4.39]$ \\
\hline Goosebumps or hair standing up & $2.62(2.19)$ & $3.19[2.85,3.53]$ & $3.29[2.63,3.95]$ & $2.63[2.33,2.94]$ & $1.11[0.63,1.59]$ \\
\hline Chills or shivers & $1.82(1.91)$ & $1.94[1.63,2.24]$ & $2.74[2.15,3.33]$ & $1.96[1.69,2.23]$ & $0.78[0.35,1.21]$ \\
\hline A warm feeling in the center of the chest & $4.66(1.48)$ & $4.89[4.66,5.12]$ & $4.50[4.05,4.95]$ & $4.92[4.71,5.13]$ & $3.67[3.34,3.99]$ \\
\hline Refreshed, energized, or exhilarated & $3.90(1.75)$ & $3.99[3.71,4.28]$ & $4.18[3.63,4.74]$ & $3.66[3.40,3.91]$ & $4.15[3.75,4.56]$ \\
\hline Buoyant or light & $3.66(1.80)$ & $3.62[3.32,3.91]$ & $3.95[3.37,4.52]$ & $3.60[3.33,3.86]$ & $3.78[3.36,4.20]$ \\
\hline I laughed & $3.26(2.24)$ & $2.76[2.44,3.08]$ & $2.37[1.74,2.99]$ & $2.86[2.57,3.15]$ & $5.71[5.25,6.16]$ \\
\hline I giggled & $2.87(2.23)$ & $2.40[2.07,2.73]$ & $1.87[1.23,2.51]$ & $2.60[2.31,2.90]$ & $5.03[4.56,5.49]$ \\
\hline I felt an incredible bond & $4.34(1.93)$ & $4.13[3.82,4.43]$ & $3.89[3.30,4.49]$ & $4.94[4.66,5.21]$ & $3.53[3.10,3.96]$ \\
\hline I felt an exceptional sense of closeness appear & $4.18(1.94)$ & $4.07[3.76,4.38]$ & $3.71[3.11,4.31]$ & $4.71[4.43,4.98]$ & $3.32[2.89,3.75]$ \\
\hline Affection $(\alpha=.88)$ & $4.26(1.83)$ & $4.10[3.81,4.39]$ & $3.80[3.24,4.36]$ & $4.82[4.56,5.08]$ & $3.42[3.02,3.83]$ \\
\hline $\begin{array}{l}\text { I felt that either I or someone else delivered an } \\
\text { extraordinary performance }\end{array}$ & $3.63(2.22)$ & $4.37[4.02,4.73]$ & $3.21[2.52,3.90]$ & $3.28[2.96,3.59]$ & $3.25[2.75,3.75]$ \\
\hline $\begin{array}{l}\text { I felt that either I or someone else overcame an } \\
\text { obstacle }\end{array}$ & $3.45(2.28)$ & $4.65[4.32,4.98]$ & $2.18[1.55,2.82]$ & $3.54[3.25,3.83]$ & $1.53[1.07,1.99]$ \\
\hline Achievement $(\alpha=.47)$ & $3.54(1.82)$ & $4.51[4.24,4.78]$ & $2.70[2.17,3.22]$ & $3.41[3.16,3.65]$ & $2.39[2.01,2.77]$ \\
\hline I felt that something was especially beautiful & $4.14(2.03)$ & $4.27[3.97,4.58]$ & $5.05[4.47,5.64]$ & $4.61[4.34,4.88]$ & $2.25[1.82,2.68]$ \\
\hline I encountered greatness & $3.57(2.07)$ & $4.13[3.81,4.44]$ & $4.13[3.52,4.75]$ & $3.66[3.38,3.95]$ & $1.94[1.50,2.39]$ \\
\hline Beauty $(\alpha=.65)$ & $3.86(1.77)$ & $4.19[3.94,4.46]$ & $4.59[4.09,5.10]$ & $4.14[3.90,4.37]$ & $2.10[1.73,2.46]$ \\
\hline I felt that either I or someone else was comical & $1.95(2.27)$ & & & & \\
\hline Amusement & $1.95(2.27)$ & $0.99[.73,1.26]$ & $0.97[0.46,1.49]$ & $1.51[1.27,1.74]$ & $5.47[5.10,5.85]$ \\
\hline I felt more strongly committed to a relationship & $3.71(2.19)$ & $3.59[3.24,3.94]$ & $2.39[1.72,3.07]$ & $4.24[3.93,4.55]$ & $3.31[2.81,3.80]$ \\
\hline I was inspired & $3.99(1.87)$ & $4.48[4.20,4.77]$ & $4.50[3.94,5.06]$ & $4.10[3.84,4.36]$ & $2.49[2.08,2.89]$ \\
\hline I wanted to reflect on the experience & $4.19(1.78)$ & $4.17[3.88,4.47]$ & $4.58[4.02,5.14]$ & $4.34[4.08,4.60]$ & $3.67[3.26,4.08]$ \\
\hline I felt like joking & $1.87(2.11)$ & $1.17[0.90,1.45]$ & $0.97[0.43,1.51]$ & $1.49[1.24,1.74]$ & $4.67[4.27,5.06]$ \\
\hline I felt admiration & $4.31(1.89)$ & $4.73[4.43,5.02]$ & $4.21[3.64,4.78]$ & $4.56[4.29,4.82]$ & $2.94[2.53,3.36]$ \\
\hline I felt pride & $4.37(1.90)$ & $5.29[5.01,5.56]$ & $4.00[3.47,4.53]$ & $4.45[4.20,4.70]$ & $2.57[2.18,2.96]$ \\
\hline
\end{tabular}




\begin{tabular}{|c|c|c|c|c|c|}
\hline I felt respect & $4.13(1.88)$ & $4.43[4.13,4.72]$ & $4.21[3.64,4.78]$ & $4.42[4.16,4.68]$ & $2.76[2.35,3.18]$ \\
\hline I was awed & $3.86(1.97)$ & $4.20[3.91,4.50]$ & $5.13[4.56,5.70]$ & $4.03[3.77,4.30]$ & $2.10[1.68,2.51]$ \\
\hline I felt inspired & $3.96(1.92)$ & $4.65[4.36,4.94]$ & $4.24[3.68,4.80]$ & $4.02[3.76,4.28]$ & $2.26[1.86,2.67]$ \\
\hline I felt gratitude & $4.18(1.93)$ & $4.58[4.29,4.87]$ & $4.29[3.73,4.85]$ & $4.54[4.28,4.80]$ & $2.43[2.02,2.84]$ \\
\hline I felt compassionate & $4.01(1.92)$ & $4.01[3.72,4.31]$ & $3.95[3.37,4.52]$ & $4.56[4.30,4.83]$ & $2.65[2.23,3.07]$ \\
\hline It was heartwarming & $4.96(1.56)$ & $5.08[4.85,5.31]$ & $4.89[4.45,5.34]$ & $5.48[5.27,5.68]$ & $3.47[3.15,3.80]$ \\
\hline I was moved & $4.65(1.83)$ & $4.92[4.67,5.16]$ & $5.05[4.57,5.53]$ & $5.30[5.08,5.52]$ & $2.32[1.97,2.67]$ \\
\hline I was touched & $4.46(1.92)$ & $4.47[4.21,4.73]$ & $5.05[4.55,5.55]$ & $5.26[5.03,5.50]$ & $2.13[1.76,2.49]$ \\
\hline Kama Muta $(\alpha=.90)$ & $4.69(1.61)$ & $4.82[4.61,5.04]$ & $5.00[4.58,5.42]$ & $5.35[5.16,5.54]$ & $2.64[2.34,2.94]$ \\
\hline I felt love & $4.57(1.95)$ & $4.63[4.32,4.94]$ & $4.55[3.96,5.15]$ & $5.01[4.74,5.29]$ & $3.38[2.94,3.81]$ \\
\hline I felt sad & $1.14(1.63)$ & $1.03[0.71,1.35]$ & $1.38[1.07,1.68]$ & $1.37[1.05,1.69]$ & $0.82[0.55,1.10]$ \\
\hline I was amused & $2.68(2.19)$ & $1.88[1.58,2.18]$ & $2.00[1.42,2.58]$ & $2.37[2.10,2.63]$ & $5.39[4.97,5.81]$ \\
\hline I was entertained & $3.37(2.16)$ & $2.80[2.49,3.12]$ & $3.84[3.23,4.46]$ & $2.89[2.60,3.17]$ & $5.46[5.01,5.91]$ \\
\hline
\end{tabular}

Note: The predicted category for each item is indicated in bold. 
Table 5

Overview of descriptives including means and standard deviations in Study 4a across the positive tear categories and negative tears for each country separately

Country $n \quad$ Age Positive Tears

\begin{tabular}{|c|c|c|c|c|c|c|c|c|}
\hline & Female & Male & Achievement & Beauty & Affection & Amusement & Total & \\
\hline Australia & 183 & 63 & $2.23(1.36)$ & $2.37(1.38)$ & $3.00(1.42)$ & $4.73(1.82)$ & $2.85(1.08)$ & $3.76(1.17)$ \\
\hline Austria & 50 & 29 & $1.47(0.79)$ & $2.14(1.12)$ & $2.06(1.14)$ & $4.41(2.05)$ & $2.25(0.83)$ & 3.27 (1.19) \\
\hline Belgium & 171 & 51 & $1.71(0.95)$ & $2.73(1.45)$ & $2.35(1.22)$ & $4.35(1.87)$ & $2.56(0.90)$ & 3.47 (1.13) \\
\hline Brazil & 245 & 174 & $2.56(1.48)$ & $2.07(1.24)$ & $3.13(1.57)$ & $3.77(2.13)$ & $2.76(1.08)$ & 3.54 (1.40) \\
\hline Bulgaria & 51 & 50 & $1.64(0.93)$ & $1.92(1.21)$ & $2.26(1.40)$ & $2.79(2.11)$ & $2.06(1.00)$ & 2.87 (1.17) \\
\hline Chile & 55 & 53 & $1.88(1.04)$ & $2.06(1.42)$ & $2.24(1.13)$ & $3.00(2.10)$ & $2.19(0.95)$ & 3.22 (1.19) \\
\hline China & 103 & 72 & $2.35(1.29)$ & $2.37(1.37)$ & $2.91(1.49)$ & $2.34(1.67)$ & $2.52(1.06)$ & $3.50(1.33)$ \\
\hline Finland & 49 & 55 & $1.56(0.87)$ & $2.41(1.30)$ & $1.84(0.90)$ & $2.68(1.82)$ & $2.05(0.85)$ & $3.28(1.23)$ \\
\hline Germany & 50 & 39 & $1.53(0.89)$ & $2.24(1.40)$ & $2.45(1.33)$ & - & $2.08(1.04)$ & $3.22(1.16)$ \\
\hline Ghana & 53 & 54 & $2.06(1.40)$ & $1.99(1.24)$ & $2.42(1.51)$ & $3.72(2.18)$ & $2.38(1.12)$ & $3.23(1.15)$ \\
\hline Greece & 79 & 37 & $1.91(1.07)$ & $1.70(1.00)$ & $2.38(1.19)$ & $3.47(2.01)$ & $2.21(0.87)$ & $3.51(1.31)$ \\
\hline Hungary & 48 & 34 & $1.49(0.87)$ & $2.23(1.49)$ & $2.07(1.21)$ & 3.67 (1.97) & $2.18(1.06)$ & 2.89 (1.24) \\
\hline Iceland & 180 & 146 & $1.22(0.55)$ & $1.58(0.96)$ & $1.96(1.20)$ & $3.17(1.84)$ & $1.81(0.73)$ & $2.71(1.15)$ \\
\hline India & 112 & 162 & $2.06(1.30)$ & $1.93(1.23)$ & $2.67(1.51)$ & $2.95(2.03)$ & $2.33(1.10)$ & 2.94 (1.18) \\
\hline Indonesia & 118 & 53 & $2.80(1.55)$ & $1.98(1.18)$ & $2.92(1.51)$ & $2.38(1.84)$ & 2.54 (1.14) & 3.37 (1.48) \\
\hline Israel & 50 & 47 & $1.22(0.53)$ & $1.84(1.19)$ & $1.84(0.95)$ & $3.25(1.99)$ & $1.86(0.70)$ & 3.14 (1.39) \\
\hline Italy & 79 & 35 & $2.04(1.44)$ & $2.71(1.61)$ & $2.21(1.20)$ & - & $2.32(1.10)$ & $3.26(1.17)$ \\
\hline Jamaica & 64 & 34 & $2.24(1.23)$ & $2.13(1.34)$ & $2.69(1.53)$ & $4.31(2.02)$ & $2.64(1.10)$ & 3.44 (1.13) \\
\hline Japan & 80 & 201 & $2.25(1.27)$ & $1.80(1.17)$ & $2.10(1.14)$ & $2.38(1.81)$ & $2.10(0.94)$ & 2.87 (1.07) \\
\hline Kenya & 82 & 85 & $2.17(1.70)$ & $1.74(1.24)$ & $2.62(1.71)$ & $4.01(2.55)$ & $2.44(1.22)$ & $3.86(1.47)$ \\
\hline Korea & 228 & 187 & $2.16(1.22)$ & $2.24(1.33)$ & $2.57(1.37)$ & $3.28(2.00)$ & $2.46(1.04)$ & 3.45 (1.21) \\
\hline Lithuania & 135 & 53 & $1.60(0.99)$ & $2.47(1.45)$ & $2.32(1.26)$ & $4.72(1.70)$ & $2.50(1.00)$ & 3.05 (1.08) \\
\hline Malaysia & 48 & 43 & $2.18(1.20)$ & $1.48(0.82)$ & $2.42(1.36)$ & $2.62(1.93)$ & $2.11(0.90)$ & 3.00 (1.37) \\
\hline Nepal & 47 & 53 & $2.89(1.55)$ & $2.72(1.45)$ & $2.88(1.23)$ & $2.94(1.93)$ & $2.85(1.11)$ & 3.79 (1.30) \\
\hline Netherlands & 78 & 85 & $1.69(0.98)$ & $2.08(1.20)$ & $2.50(1.42)$ & $3.69(2.08)$ & $2.32(0.99)$ & $3.17(1.38)$ \\
\hline
\end{tabular}




\begin{tabular}{|c|c|c|c|c|c|c|c|c|}
\hline New Zealand & 49 & 26 & $1.79(0.97)$ & $2.47(1.32)$ & $2.52(1.30)$ & - & $2.27(1.00)$ & $3.48(1.19)$ \\
\hline Nigeria & 41 & 57 & $2.37(1.61)$ & $2.19(1.37)$ & $2.27(1.57)$ & $3.17(2.33)$ & $2.41(1.16)$ & $3.48(1.34)$ \\
\hline Peru & 48 & 45 & $2.69(1.23)$ & $2.56(1.09)$ & $2.62(1.12)$ & $2.95(1.66)$ & $2.67(0.80)$ & $3.21(0.82)$ \\
\hline Poland & 56 & 53 & $1.59(0.94)$ & $1.89(1.08)$ & $2.12(1.18)$ & $4.04(2.08)$ & $2.17(0.87)$ & $2.84(1.25)$ \\
\hline Portugal & 64 & 63 & $1.89(0.96)$ & $1.92(1.11)$ & $2.06(0.93)$ & $2.63(2.10)$ & $2.20(0.78)$ & $2.98(1.05)$ \\
\hline Romania & 91 & 77 & $1.76(1.10)$ & $2.21(1.28)$ & $1.78(1.01)$ & $2.74(1.95)$ & $2.04(0.85)$ & $2.54(1.11)$ \\
\hline Spain & 52 & 50 & $1.56(0.85)$ & $2.45(1.29)$ & $2.86(1.42)$ & $4.46(2.00)$ & $2.65(1.01)$ & $3.42(1.20)$ \\
\hline Sweden & 50 & 47 & $1.74(0.92)$ & $2.45(1.29)$ & $2.78(1.38)$ & $3.73(1.92)$ & $2.53(0.95)$ & $3.50(1.24)$ \\
\hline Switzerland & 67 & 51 & $1.73(1.12)$ & $2.34(1.30)$ & $1.86(0.85)$ & $3.96(2.21)$ & $2.26(0.88)$ & $2.94(1.13)$ \\
\hline Turkey & 52 & 50 & $2.23(1.21)$ & $1.75(1.08)$ & $2.68(1.40)$ & $2.31(1.82)$ & $2.23(0.94)$ & $3.21(1.18)$ \\
\hline United Kingdom & 51 & 32 & $2.27(1.43)$ & $1.93(1.27)$ & $2.93(1.68)$ & $3.76(2.16)$ & $2.58(1.08)$ & $3.08(1.21)$ \\
\hline United States & 160 & 51 & $1.97(1.19)$ & $2.50(1.40)$ & $2.63(1.42)$ & $4.27(1.92)$ & $2.64(1.10)$ & $3.73(1.27)$ \\
\hline Total & 3218 & 2497 & $2.00(1.26)$ & $2.14(1.32)$ & $2.47(1.39)$ & $3.46(2.10)$ & $2.37(1.03)$ & $3.26(1.27)$ \\
\hline
\end{tabular}

Table 6

Separate multilevel models for variables concerning the reported tear episode.

\begin{tabular}{|c|c|c|c|c|c|}
\hline Variable & $B[95 \% \mathrm{CI}]$ & $t(\mathrm{df})$ & $p$ & $M_{n e g}[95 \% \mathrm{CI}]$ & $M_{p o s}[95 \% \mathrm{CI}]$ \\
\hline Last Crying Episode & $-.06[-.21, .07]$ & $-.94(5524)$ & .345 & $3.89[3.72,4.07]$ & $3.82[3.61,4.03]$ \\
\hline Duration & $-.84[-.97,-.71]$ & $-12.47(5539)$ & $<.001$ & $2.31[2.21,2.41]$ & $1.47[1.33,1.62]$ \\
\hline Intensity & $-.50[-.57,-.43]$ & $-13.77(5528)$ & $<.001$ & $2.01[1.94,2.08]$ & $1.50[1.41,1.59]$ \\
\hline Time passed & $-.78[-.97,-.59]$ & $-7.91(5526)$ & $<.001$ & $2.13[1.98,2.28]$ & $1.35[1.13,1.57]$ \\
\hline Time of day & $7283.89[1772.47,12795.11]$ & $2.59(4962)$ & .01 & $152689[143092,162285]$ & 159973 [149357, 170588] \\
\hline Number of people (log) & $.35[.25, .46]$ & $6.75(5437)$ & $<.001$ & $.88[.81, .95]$ & $1.24[1.13,1.35]$ \\
\hline Mental state after & $.24[.19, .30]$ & $8.53(5532)$ & $<.001$ & $2.32[2.28,2.36]$ & $2.56[2.50,2.62]$ \\
\hline Physical state after & $.24[.18, .29]$ & $8.53(5500)$ & $<.001$ & $2.05[2.02,2.08]$ & $2.28[2.23,2.34]$ \\
\hline Relationship Change & $.07[.01, .14]$ & $2.40(3278)$ & .016 & $2.15[2.11,2.19]$ & $2.23[2.16,2.29]$ \\
\hline Situation Change & $.14[.07, .20]$ & $4.18(3891)$ & $<.001$ & $2.18[2.13,2.23]$ & $2.32[2.24,2.39]$ \\
\hline
\end{tabular}


Table 7

Regression analysis regressing category on the Big 5 traits for each positive tear category separately. Results are presented for the overall sample and for Norway (NO), the US, and Serbia (SE) separately.

\begin{tabular}{|c|c|c|c|c|c|c|c|c|c|c|}
\hline Predictor & $b$ & $\begin{array}{c}b \\
95 \% \mathrm{CI} \\
{[\mathrm{LL}, \mathrm{UL}]}\end{array}$ & beta & $\begin{array}{c}\text { beta } \\
95 \% \text { CI } \\
{[\mathrm{LL}, \mathrm{UL}]}\end{array}$ & $s r^{2}$ & $\begin{array}{c}s r^{2} \\
95 \% \mathrm{CI} \\
{[\mathrm{LL}, \mathrm{UL}]}\end{array}$ & $r$ & $\mathrm{NO}$ & US & SE \\
\hline $\begin{array}{l}\text { Achievement } \\
\text { (Intercept) }\end{array}$ & $\begin{aligned} R^{2} & =.052 \\
& 0.20\end{aligned}$ & $\begin{array}{c}.02, .08] \\
{[-0.72,1.12]}\end{array}$ & & & & & & & & \\
\hline Extraversion & $0.18 * *$ & {$[0.10,0.26]$} & 0.17 & {$[0.10,0.25]$} & .03 & {$[.00, .05]$} & $.17 * *$ & $0.07[-0.06,0.21]$ & $0.29[0.18,0.40]$ & $0.21[0.09,0.32]$ \\
\hline Agreeableness & $0.12 *$ & {$[0.01,0.23]$} & 0.09 & {$[0.01,0.17]$} & .01 & {$[-.00, .02]$} & $.11 * *$ & $-0.04[-0.18,0.09]$ & $0.26[0.14,0.37]$ & $0.11[-0.01,0.23]$ \\
\hline Conscientiousness & 0.05 & {$[-0.05,0.15]$} & 0.04 & {$[-0.04,0.12]$} & .00 & {$[-.00, .01]$} & .04 & $0.17[0.04,0.30]$ & $-0.15[-0.26,-0.03]$ & $0.10[-0.02,0.22]$ \\
\hline Neuroticism & $0.16 * *$ & {$[0.07,0.24]$} & 0.15 & {$[0.07,0.22]$} & .02 & {$[-.00, .04]$} & .06 & $0.21[0.09,0.34]$ & $0.21[0.10,0.32]$ & $0.10[-0.02,0.22]$ \\
\hline Openness & 0.05 & {$[-0.04,0.14]$} & 0.04 & {$[-0.03,0.11]$} & .00 & {$[-.00, .01]$} & .06 & $0.06[-0.08,0.19]$ & $0.00[-0.12,0.12]$ & $0.12[0.00,0.24]$ \\
\hline $\begin{array}{l}\text { Beauty } \\
\text { (Intercept) }\end{array}$ & $\begin{array}{c}R^{2}=.056 \\
1.04 *\end{array}$ & $\begin{array}{c}{[.02, .09]} \\
{[0.13,1.95]}\end{array}$ & & & & & & & & \\
\hline Extraversion & 0.01 & {$[-0.07,0.08]$} & 0.01 & {$[-0.07,0.08]$} & .00 & {$[-.00, .00]$} & .02 & $-0.12[-0.25,0.01]$ & $0.22[0.11,0.33]$ & $-0.07[-0.19,0.05]$ \\
\hline Agreeableness & 0.04 & {$[-0.07,0.15]$} & 0.03 & {$[-0.05,0.11]$} & .00 & {$[-.00, .00]$} & .01 & $-0.17[-0.30,-0.04]$ & $0.22[0.10,0.33]$ & $0.05[-0.07,0.17]$ \\
\hline Conscientiousness & -0.09 & {$[-0.19,0.01]$} & -0.07 & {$[-0.15,0.01]$} & .00 & {$[-.00, .01]$} & -.07 & $0.02[-0.11,0.16]$ & $-0.17[-0.28,-0.05]$ & $-0.11[-0.23,0.01]$ \\
\hline Neuroticism & $0.09 *$ & {$[0.01,0.17]$} & 0.08 & {$[0.01,0.16]$} & .01 & {$[-.00, .02]$} & $.07 *$ & $0.10[-0.03,0.24]$ & $0.23[0.12,0.34]$ & $0.04[-0.08,0.16]$ \\
\hline Openness & $0.27 * *$ & {$[0.18,0.36]$} & 0.22 & {$[0.14,0.29]$} & .04 & {$[.02, .07]$} & $.21 * *$ & $0.25[0.12,0.38]$ & $0.09[-0.03,0.21]$ & $0.47[0.38,0.57]$ \\
\hline $\begin{array}{l}\text { Affection } \\
\text { (Intercept) }\end{array}$ & $\begin{array}{c}R^{2}=.070 \\
-0.23\end{array}$ & $\begin{array}{c}{[.03, .10]} \\
{[-1.19,0.74]}\end{array}$ & & & & & & & & \\
\hline Extraversion & $0.09 *$ & {$[0.01,0.17]$} & 0.08 & {$[0.01,0.15]$} & .01 & {$[-.00, .02]$} & $.10 * *$ & $-0.04[-0.17,0.10]$ & $0.21[0.10,0.32]$ & $0.11[-0.01,0.22]$ \\
\hline Agreeableness & $0.30 * *$ & {$[0.19,0.42]$} & 0.21 & {$[0.13,0.29]$} & .03 & {$[.01, .06]$} & $.18^{* *}$ & $0.15[0.02,0.28]$ & $0.46[0.37,0.56]$ & $0.29[0.18,0.40]$ \\
\hline Conscientiousness & 0.02 & {$[-0.09,0.12]$} & 0.01 & {$[-0.07,0.09]$} & .00 & {$[-.00, .00]$} & .04 & $0.15[0.02,0.28]$ & $-0.06[-0.18,0.05]$ & $-0.01[-0.13,0.11]$ \\
\hline Neuroticism & $0.22 * *$ & {$[0.13,0.30]$} & 0.19 & {$[0.11,0.27]$} & .03 & {$[.01, .05]$} & $.10 * *$ & $0.13[-0.01,0.26]$ & $0.31[0.20,0.42]$ & $0.26[0.15,0.37]$ \\
\hline Openness & 0.09 & {$[-0.00,0.18]$} & 0.07 & {$[-0.00,0.14]$} & .00 & {$[-.00, .01]$} & $.09 *$ & $0.07[-0.07,0.20]$ & $-0.03[-0.15,0.09]$ & $0.23[0.12,0.35]$ \\
\hline $\begin{array}{l}\text { Amusement } \\
\text { (Intercept) }\end{array}$ & $\begin{array}{c}R^{2}=.048 \\
1.83 * *\end{array}$ & $\begin{array}{c}{[.02, .08]} \\
{[0.80,2.85]}\end{array}$ & & & & & & & & \\
\hline Extraversion & $0.17 * *$ & {$[0.09,0.26]$} & 0.15 & {$[0.08,0.23]$} & .02 & {$[.00, .04]$} & $.16^{* *}$ & $0.17[0.04,0.30]$ & $0.20[0.09,0.32]$ & $0.10[-0.02,0.22]$ \\
\hline Agreeableness & 0.08 & {$[-0.05,0.20]$} & 0.05 & {$[-0.03,0.13]$} & .00 & {$[-.00, .01]$} & .05 & $0.02[-0.12,0.15]$ & $0.22[0.11,0.33]$ & $0.06[-0.06,0.18]$ \\
\hline Conscientiousness & $-0.13^{*}$ & {$[-0.24,-0.02]$} & -0.09 & {$[-0.17,-0.01]$} & .01 & {$[-.00, .02]$} & -.07 & $0.02[-0.15,0.12]$ & $-0.05[-0.17,0.07]$ & $-0.11[-0.23,0.01]$ \\
\hline Neuroticism & 0.07 & {$[-0.03,0.16]$} & 0.06 & {$[-0.02,0.13]$} & .00 & {$[-.00, .01]$} & .02 & $-0.04[-0.17,0.10]$ & $0.23[0.12,0.35]$ & $-0.12[-0.24,-0.00]$ \\
\hline Openness & $0.15 * *$ & {$[0.05,0.25]$} & 0.11 & {$[0.04,0.18]$} & .01 & {$[-.00, .03]$} & $.13 * *$ & $0.22[0.09,0.34]$ & $0.04[-0.08,0.15]$ & $0.22[0.11,0.34]$ \\
\hline
\end{tabular}


the standardized regression weights. $s r^{2}$ represents the semi-partial correlation squared. $r$ represents the zero-order correlation. $L L$ and $U L$ indicate the lower and upper limits of a confidence interval, respectively.

$*$ indicates $p<.05 . * *$ indicates $p<.01$. 
Table 8

Overview of the different positive tear categories and their tested (bold) and postulated aspects and mechanisms.

\begin{tabular}{|c|c|c|c|c|}
\hline Aspect & & Type of & & \\
\hline & Achievement & Beauty & Affection & Amusement \\
\hline Appraisal/Elicitor & $\begin{array}{l}\text { Extraordinary } \\
\text { performance/success }\end{array}$ & $\begin{array}{l}\text { Extraordinary } \\
\text { (aesthetic) } \\
\text { beauty/elegance }\end{array}$ & $\begin{array}{l}\text { Extraordinary } \\
\text { closeness }\end{array}$ & Especially funny \\
\hline Sensation & - & $\begin{array}{l}\text { Chills, } \\
\text { Goosebumps }\end{array}$ & $\begin{array}{l}\text { Warmth in the } \\
\text { body }\end{array}$ & $\begin{array}{l}\text { Laughing, } \\
\text { Giggling }\end{array}$ \\
\hline Motivation & Inspiration, Modelling & Reflection & Approaching & Joking \\
\hline Feeling Label & $\begin{array}{l}\text { Pride, Admiration, } \\
\text { Inspiration, Gratitude }\end{array}$ & Awe, Moved & $\begin{array}{l}\text { Moved, Touched, } \\
\text { Heartwarming, } \\
\text { Love, Compassion }\end{array}$ & $\begin{array}{l}\text { Amused, } \\
\text { Entertained }\end{array}$ \\
\hline Related Emotions & $\begin{array}{l}\text { Pride, Admiration, } \\
\text { Inspiration, (Social) Awe }\end{array}$ & $\begin{array}{l}\text { (Nature) Awe, } \\
\text { Wonder }\end{array}$ & $\begin{array}{l}\text { Compassion, Kama } \\
\text { Muta, Love, } \\
\text { Tenderness, } \\
\text { Sympathy }\end{array}$ & $\begin{array}{l}\text { Amusement, } \\
\text { Mirth }\end{array}$ \\
\hline $\begin{array}{l}\text { Emotion Family } \\
\text { (Graham et al., 2017; } \\
\text { Sauter, 2017) }\end{array}$ & $\begin{array}{l}\text { Other-praising/Self- } \\
\text { praising; Agency- } \\
\text { approach/Prosocial }\end{array}$ & $\begin{array}{l}\text { Violation-elicited; } \\
\text { Epistemological }\end{array}$ & $\begin{array}{l}\text { Affectionate; } \\
\text { Prosocial }\end{array}$ & $\begin{array}{l}\text { Violation- } \\
\text { elicited; } \\
\text { Epistemological }\end{array}$ \\
\hline $\begin{array}{l}\text { Crying Type } \\
\text { (Denckla et al., } \\
\text { 2014) }\end{array}$ & Sentimental & Sentimental & Attachment & - \\
\hline Personality & Extraversion & $\begin{array}{l}\text { Openness to } \\
\text { Experiences }\end{array}$ & $\begin{array}{l}\text { Agreeableness, } \\
\text { Empathy }\end{array}$ & Extraversion \\
\hline
\end{tabular}


Figures

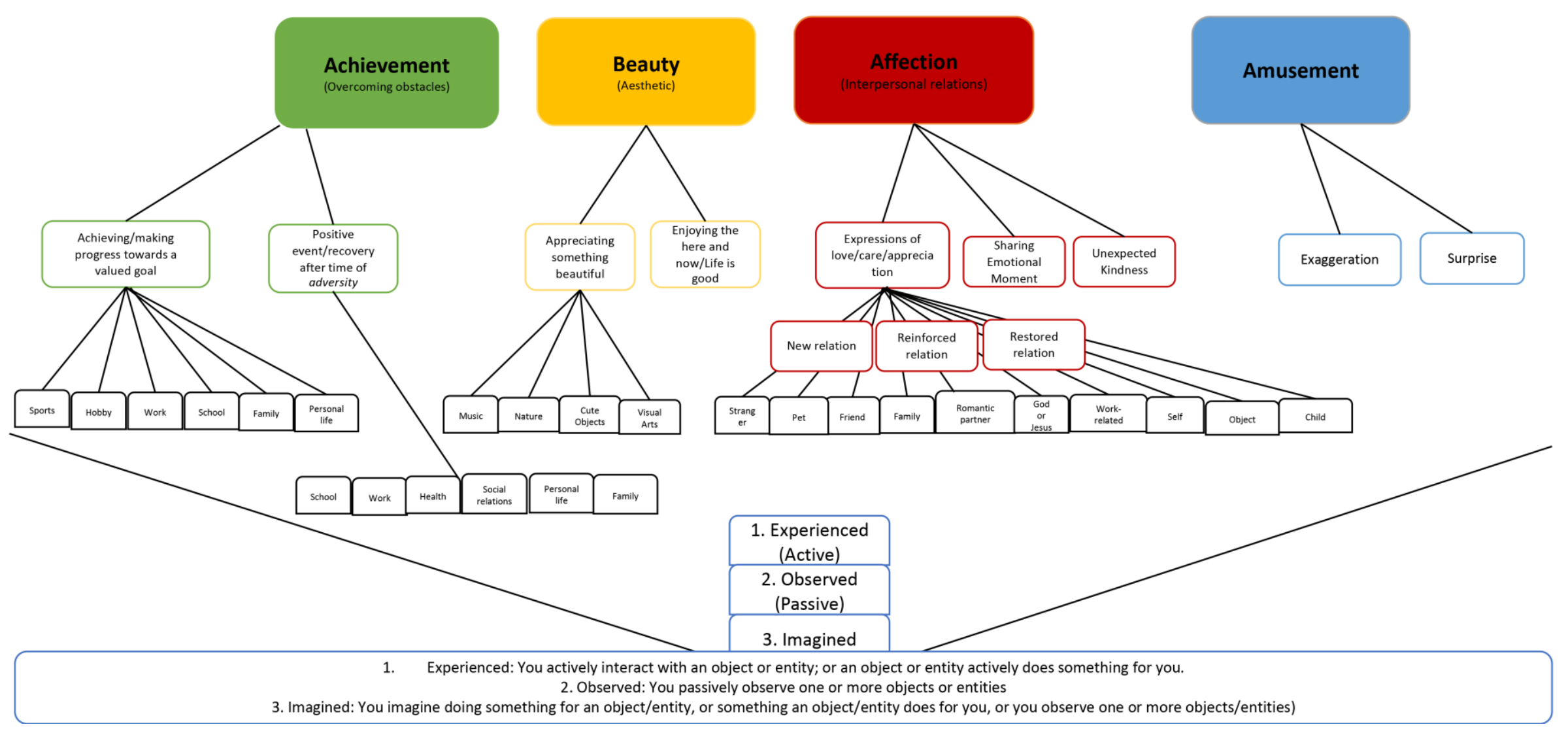

Figure 1. The final version of the model of positive tears. The first level indicates the main categories, the second level subcategories, and the third level the object or topic of the episode. Each category can occur as experienced, observed or imagined. 

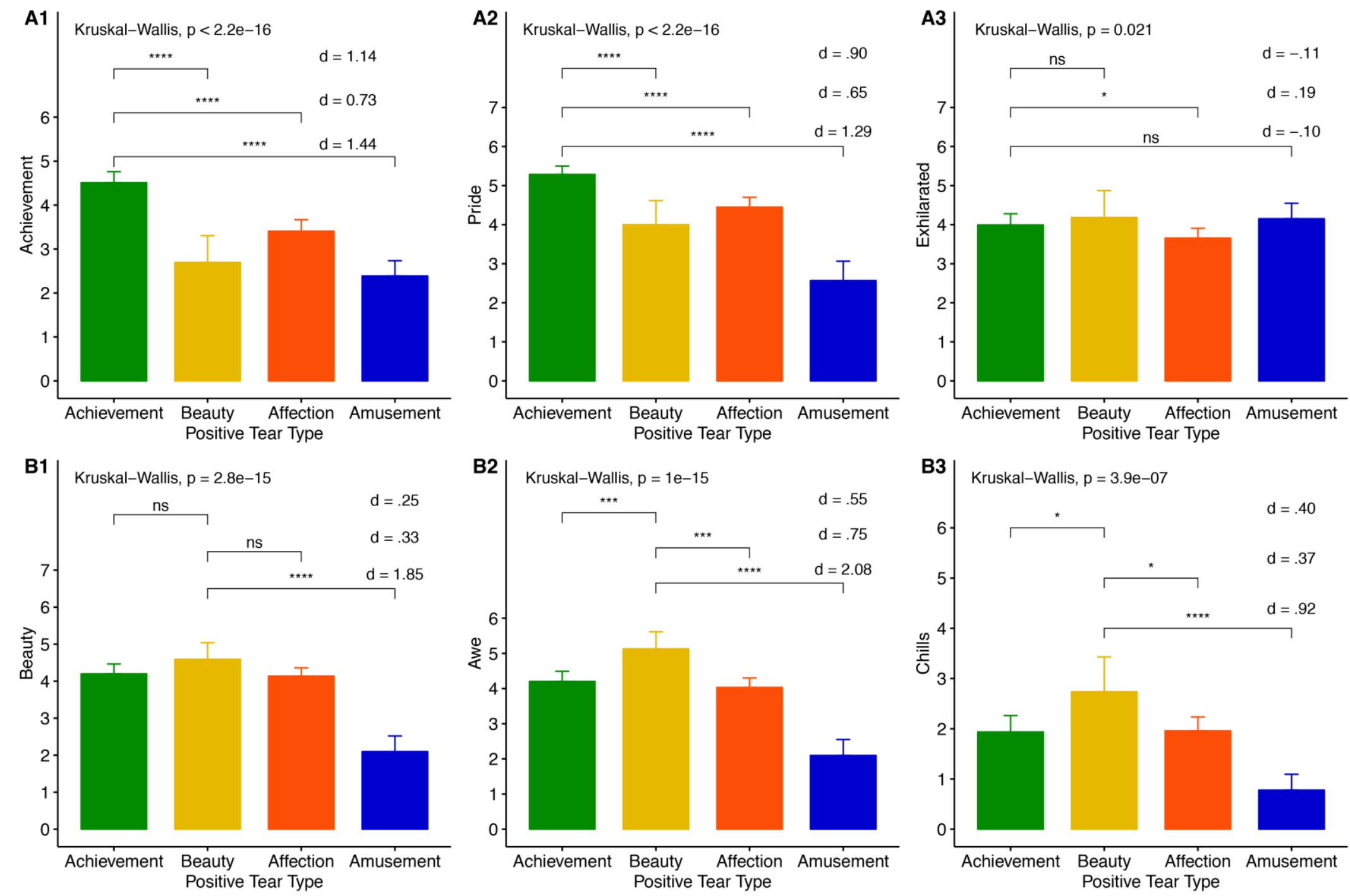

Figure 2.1. Bar plots across the coded positive tears types in Study 3 for the achievement appraisal (A1), the beauty appraisal (B1), feeling pride (A2), feeling awe (B2), experiencing exhilaration (A3) and chills (B3). Error bars represent 95\% confidence intervals. 

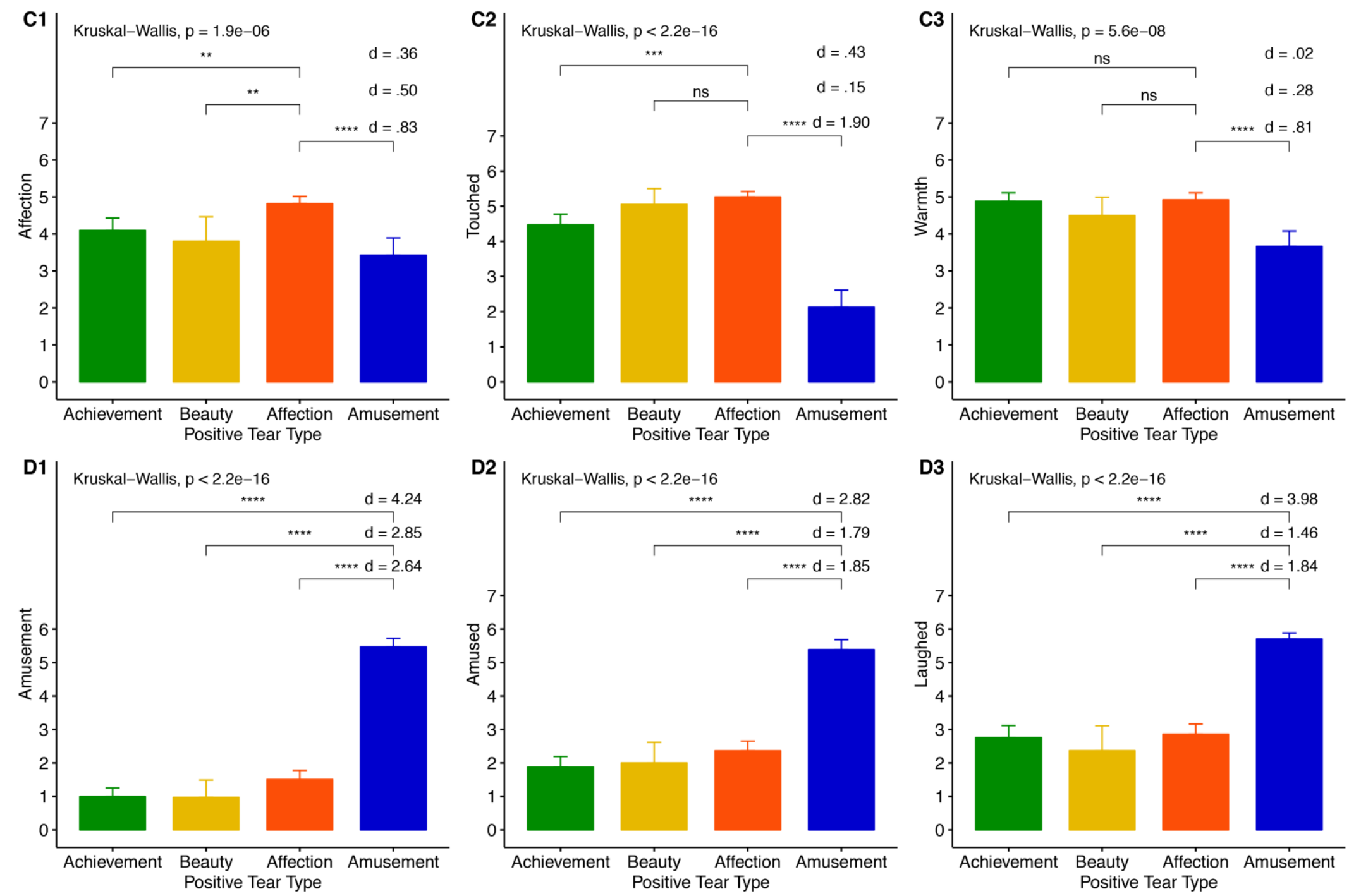

Figure 2.2. Bar plots across the coded positive tears types in Study 3 for the affection appraisal (C1), the amusement appraisal (D1), feeling touched (C2), feeling amused (D2), experiencing warmth in the chest (C3) and laughing (D3). Error bars represent $95 \%$ confidence intervals 